\title{
Hydrogen sulfide and potassium synergistically induce osmotic stress tolerance through regulation of H+-ATPase activity and sugar metabolism in tomato seedlings
}

Manzer H. Siddiqui ( $\nabla$ manzerhs@yahoo.co.in )

King Saud University https://orcid.org/0000-0003-2840-4608

Soumya Mukherjee

University of Kalyani

Saud Alamri

King Saud University

Yanbo Hu

Northeast Forestry University

Abdullah Alamri

King Saud University

Qasi Alsubaie

King Saud University

Bander Al-Munqedhi

King Saud University

Hayssam Ali

King Saud University

Research Article

Keywords: Carbohydrates, hydrogen sulfide, osmolytes, oxidative stress, potassium homeostasis

Posted Date: March 23rd, 2021

DOl: https://doi.org/10.21203/rs.3.rs-277344/v1

License: (c) (i) This work is licensed under a Creative Commons Attribution 4.0 International License.

Read Full License 


\section{Abstract}

Potassium (K) is an essential macronutrient which is known to regulate key metabolic processes, modulate enzyme activity and plays a decisive role in osmotic adjustment in plants. Present work evaluates the role of $\mathrm{K}$ in the regulation of endogenous hydrogen sulfide $\left(\mathrm{H}_{2} \mathrm{~S}\right)$ signaling in modulating the tolerance of tomato (Solanum lycopersicum L. Mill.) seedlings to osmotic stress. The findings reveal that exposure of seedlings to $15 \%(\mathrm{w} / \mathrm{v})$ polyethylene glycol $8000(\mathrm{PEG})$ led to a substantial decrease in leaf $\mathrm{K}$ content which was associated with reduced $\mathrm{H}^{+}$-ATPase activity. Exogenous application of $\mathrm{K}$ to the stressed seedlings significantly improved endogenous $\mathrm{K}$ content. Treatment with sodium orthovanadate (SOV, PM H${ }^{+}$-ATPase inhibitor) and tetraethylammonium chloride (TEA, $\mathrm{K}$ channel blocker) suggests that exogenous $\mathrm{K}$ stimulated $\mathrm{H}^{+}$-ATPase activity that further regulated endogenous $\mathrm{K}$ content in tomato seedlings subjected to osmotic stress. Moreover, reduction in $\mathrm{H}^{+}$-ATPase activity by hypotaurine $\left(\mathrm{H}_{2} \mathrm{~S}\right.$ scavenger) substantiates the role of endogenous $\mathrm{H}_{2} \mathrm{~S}$ in the regulation of $\mathrm{H}^{+}$-ATPase activity. Elevation in endogenous $\mathrm{K}$ content enhanced the biosynthesis of hydrogen sulfide $\left(\mathrm{H}_{2} \mathrm{~S}\right)$ through enhancing the synthesis of cysteine, the $\mathrm{H}_{2} \mathrm{~S}$ precursor. Synergistic action of $\mathrm{H}_{2} \mathrm{~S}$ and $\mathrm{K}$ effectively neutralized osmotic stress by regulating sugar metabolism that resulted in osmotic adjustment, as witnessed by reduced water loss and improved hydration level of the stressed seedlings. Cross talk of $\mathrm{H}_{2} \mathrm{~S}$ and $\mathrm{K}$ also assisted the seedlings in the activation of antioxidant enzymes that controlled the generation of reactive oxygen species and led to the protection against oxidative stress. The integrative role of $\mathrm{H}_{2} \mathrm{~S}$ and $\mathrm{K}$ signaling was validated using hypotaurine $\left(\mathrm{H}_{2} \mathrm{~S}\right.$ scavenger) and TEA ( $\mathrm{K}$ channel blocker) which weakened the protection against osmotic stress induced impairments. In conclusion, exogenous $\mathrm{K}$ and endogenous $\mathrm{H}_{2} \mathrm{~S}$ regulate $\mathrm{H}^{+}$-ATPase activity which plays a decisive role in the maintenance of endogenous $\mathrm{K}$ homeostasis. Thus, present work reveals that $\mathrm{K}$ and $\mathrm{H}_{2} \mathrm{~S}$ crosstalk is essential for modulation of osmotic stress tolerance in tomato seedlings.

\section{Key Messages}

Potassium (K) and hydrogen sulfide ( $\mathrm{H} 2 \mathrm{~S})$ crosstalk, during osmotic stress tolerance, operates through regulating $\mathrm{H}^{+}$-ATPase activity and sugar metabolism in tomato seedlings.

\section{Introduction}

Modulation of plant growth under water scarcity is important for crop sustainability and optimum yield. Owing to sedentary nature of plants, availability of optimum concentration of water in the vicinity becomes more imperative for endurance of plants. Water not only acts as medium for numerous cellular activities but assures plants access to vital nutrients required for proper growth and blossoming harvests. However, availability of water to the plants is often challenged by environmental stresses such as drought, salinity, high and low temperature, heavy metal etc. Manifestation of osmotic stress is a common attribute of these abiotic stresses that restricts water availability to the plants. Osmotic stress 
results from imbalance between extracellular and intracellular solute concentration that reduces soil osmotic potential and subsequently imposes osmotic stress to the plants. Higher solute concentration may result from excess accumulation of salt and evaporation of water from the soil that leaves behind excess of ions in the soil. Owing to accumulation of salts, osmotic pressure in soil exceeds the osmotic pressure of plant cells that restricts water and minerals availability to the plants. Osmotic stress adversely affects the cell wall integrity, apoplast $\mathrm{pH}$, cytosolic fluidity, photosynthetic activity, and structure of chloroplast and mitochondria followed by changes in gene expression, regulation of transcription factors and enzyme activities (Liu et al. 2010; García-Morales et al. 2018; Darko et al. 2019). These alterations caused by osmotic stress severely affect plants at morphological, physiological, biochemical, and molecular level (Khan et al. 2017; García-Morales et al. 2018). Under osmotic stress, depleted hydration level in plants induces leakage of potassium $(K)$ that results in hydropassive stomatal closure (Kim et al. 2010). Stomatal closure delimits $\mathrm{CO}_{2}$ availability in the mesophyll cells which results in altered primary metabolism accompanied by over production of reactive oxygen species (ROS) (Mehler 1951). Although at lower concentration ROS signaling appears to be beneficial, their higher concentration creates oxidative stress and damages macromolecules and causes deformity and dysfunction of cell membranes through peroxidation of lipids (Hasanuzzaman et al. 2020; Khan et al. 2020a, b).

Therefore, alleviation of osmotic stress appears to be an important integrative strategy against various abiotic stresses. To counter osmotic stress-induced constrains, plants should maintain osmotic, ionic, and oxidative equilibrium. In this regard, accumulation of soluble carbohydrates is one of the key strategies which plants adopt to counter osmotic stress. Carbohydrates act as osmolytes that stabilize the membranes, and as signaling molecules that trigger essential metabolic events during plant adaptive responses to various abiotic stresses (Ahmad et al. 2020a). Sucrose, the predominant soluble carbohydrate, fulfils high energy demand under stressful conditions and plays essential role in the maintenance of cellular activities, cell wall biosynthesis, respiration, and serves as a major storage carbohydrate in the form of starch for later use (Sami et al. 2016). Besides sugars, K, the essential macronutrient, has been reported to act as a substantial inorganic osmoticum and affects stomatal conductance, axial growth, and tropism in plants (Marschner 1995). Significant evidence shows the role of $\mathrm{K}$ in osmotic adjustment, nitrogen metabolism, regulation of enzyme activities, and biosynthesis of chlorophyll (Chl) (Anschütz et al. 2014; Zahoor et al. 2017a, b). However, abiotic stresses are known to induce cellular K efflux and reduction in K influx that results in K loss (Shabala and Cuin 2008) thus leading to weak protection against the stress. Therefore, maintenance of intracellular $\mathrm{K}$ homeostasis is a key factor to mediate plant adaptive responses to abiotic stresses (Anschütz et al. 2014; Khan et al. $2020 a, b)$.

Plants counter oxidative stress through the inherent antioxidative defense system which is operated through a complex network of non-enzymes and enzymes. The enzymatic antioxidant superoxide dismutase (SOD) provides first line of defense that converts superoxide $\left(\mathrm{O}_{2}{ }^{\cdot-}\right)$ to hydrogen peroxide $\left(\mathrm{H}_{2} \mathrm{O}_{2}\right)$. At lower concentration $\mathrm{H}_{2} \mathrm{O}_{2}$ participates in signaling cascade and contributes to the defense mechanisms (Hasanuzzaman et al. 2020), whereas $\mathrm{H}_{2} \mathrm{O}_{2}$ becomes phytotoxic when its increasing level 
crosses a threshold (Khan et al. 2020a, b; Siddiqui et al. 2020). However, to control $\mathrm{H}_{2} \mathrm{O}_{2}$ level, plants possess a set of enzymes such as peroxidase (POX), catalase (CAT), ascorbate peroxidase (APX), and glutathione reductase (GR). These enzymes convert $\mathrm{H}_{2} \mathrm{O}_{2}$ into water and molecular oxygen. In spite of an array of defense strategies, survival of plants depends on the activation of defense system prior to the commencement of damage. In this regard, plants possess a dedicated signaling network that assures well-timed activation of the defense system under any stressful condition.

In the last decade of investigations in plants, hydrogen sulfide $\left(\mathrm{H}_{2} \mathrm{~S}\right)$ has emerged as an endogenous gaseous transmitter and one of the key players of the signaling network. In plants, $\mathrm{H}_{2} \mathrm{~S}$ is synthesized in a cysteine (Cys) degradation reaction catalyzed by L-cysteine desulfhydrase (LCD, EC 4.4.1.1) and Dcysteine desulfhydrase (DCD; EC 4.4.1.15). Hydrogen sulfide regulates key processes of plants including seed germination, organogenesis, stomatal movement, and photosynthesis (Arif et al. 2020; Khan et al. $2017,2018,2020)$. In addition, $\mathrm{H}_{2} \mathrm{~S}$ mediates responses to various abiotic stresses and regulates oxidative and ionic homoeostasis and enzyme activities during abiotic stress tolerance in plants (Arif et al. 2020; Khan et al. 2017, 2018, 2020a; Mukherjee and Bhatla 2020). Although interaction of $\mathrm{H}_{2} \mathrm{~S}$ with other signaling molecules, phytohormones, and second messengers has been well studied (Khan et al. 2020a, b; Mukherjee and Bhatla 2020) but no substantial information is available on the role of $\mathrm{H}_{2} \mathrm{~S}$ and $\mathrm{K}$ crosstalk in plant adaptive responses to abiotic stresses. Therefore, present investigation aims to comprehend the significance of $\mathrm{K}$ in the regulation of endogenous $\mathrm{H}_{2} \mathrm{~S}$ homeostasis during tolerance of plants to osmotic stress. Role of endogenous $\mathrm{H}_{2} \mathrm{~S}$ in $\mathrm{K}$ homeostasis and their crosstalk in the regulation of carbohydrate metabolism and antioxidative defense system was also elucidated.

\section{Materials And Methods}

\subsection{Seed germination and treatments}

Role of $\mathrm{K}$ and $\mathrm{H}_{2} \mathrm{~S}$ under osmotic stress conditions was tested in tomato (Solanum lycopersicum L. Mill.) seedlings. Healthy and uniform seeds of tomato were surface sterilized with $10 \%$ sodium hypochlorite solution for $10 \mathrm{~min}$. followed by three washings with double deionized water (DDW). The sterilized seeds were germinated in filter paper-lined Petri dishes containing Raukura's nutrient solution for 10 days prior to the treatment. The Petri dishes were kept in the dark at average day/night temperature of $26 / 15 \pm 3{ }^{\circ} \mathrm{C}$ for 8 days. After 8 days, germinated seeds were transferred to the new filter paper-lined Petri dishes containing: (1) DDW (Control), (2) $5 \mathrm{mM} \mathrm{K}_{2} \mathrm{CO}_{3}(\mathrm{~K}),(3) 15 \%$ (w/v) polyethylene glycol 8000 (PEG), (4) $\mathrm{K}+\mathrm{PEG}$, (5) $\mathrm{K}+\mathrm{PEG}+1 \mathrm{mM}$ hypotaurine ( $\mathrm{K}+\mathrm{PEG}+\mathrm{HT})$, (6) $\mathrm{K}+\mathrm{PEG}+20 \mathrm{mM}$ tetraethylammonium chloride $(\mathrm{K}+\mathrm{PEG}+\mathrm{TEA})$, and (7) $\mathrm{K}+\mathrm{PEG}+\mathrm{TEA}+\mathrm{HT}$. The seedlings were treated for $24 \mathrm{~h}$ and each treatment was replicated three times. After $24 \mathrm{~h}$ of treatments, the seedling leaves were used for the estimation of various characteristics. Osmotic stress was induced by PEG, whereas TEA was used as K-channel blocker and $\mathrm{HT}$ as $\mathrm{H}_{2} \mathrm{~S}$ scavenger. 
To evaluate the $\mathrm{K}$ transport mechanism, 8-days old seedlings, raised with nutrient solution, were treated with $20 \mathrm{mM}$ TEA or $500 \mu \mathrm{M}$ sodium orthovanadate (SOV, PM H ${ }^{+}$-ATPase inhibitor) for 30 min (Zhao et al., 2018). After $30 \mathrm{~min}$. the seedlings were subjected to 15\% (w/v) PEG for $24 \mathrm{~h}$, in the presence or absence of $5 \mathrm{mM} \mathrm{K}$. After $24 \mathrm{~h}$, concentration of $\mathrm{K}$ was estimated in the leaves of the seedlings (Fig. $2 \mathrm{~A}$ and B).

\subsection{Crude enzyme extract preparation}

A crude extract was prepared from the leaves $(0.5 \mathrm{~g})$ of treated tomato seedling. The extract was used for the assay of enzymes activity. Protein quantification was carried out according to Bradford (1976) using Bovine Serum Albumin (BSA) as a standard.

\subsection{Estimation of $K$ content and plasma membrane $H^{+}$-ATPase activity}

Concentration of $\mathrm{K}$ in the leaves was estimated using flame photometer. The leaves were dried for $72 \mathrm{~h}$ at $75^{\circ} \mathrm{C}$ followed by grinding to fine powder. $1 \mathrm{~g}$ of the powder was placed in a furnace at $500{ }^{\circ} \mathrm{C}$ to get ash which was dissolved in $5 \mathrm{~mL} \mathrm{HCl}(20 \%)$. The solution was diluted to $50 \mathrm{~mL}$ using DDW and was used for the estimation of $\mathrm{K}$ content.

Activity of plasma membrane $\mathrm{H}^{+}$-ATPase (PM H${ }^{+}$-ATPase) was measured by the method of Hejl and Koster (2004) with slight modification (Majumdar and Kar 2018). The enzyme activity of $\mathrm{PM} \mathrm{H}^{+}$-ATPase was determined by quantifying the production of inorganic phosphate at the wavelength of $700 \mathrm{~nm}$.

\subsection{Estimation of starch, sucrose, and total soluble carbohydrates}

Starch was quantified spectrophotometrically at $620 \mathrm{~nm}$ by adopting the method of Kuai et al. (2014). Soluble sugar and sucrose content were also determined spectrophotometrically at $620 \mathrm{~nm}$ and $480 \mathrm{~nm}$, respectively by adopting the modified method of Xu et al. (2015).

\subsection{Estimation of the activity of carbohydrate metabolizing enzymes}

Activity of a-amylase (EC 3.2.1.1), $\beta$-amylase (EC 3.2.1.2) was measured by the method of Li et al. (2013). Assay of sucrose phosphate synthase (SPS; EC 2.4.1.14), sucrose synthase (SuSy; EC 2.4.1.13), and soluble acid invertase (SAl) was performed by adopting the method of Kalwade and Devarumath (2013).

\subsection{Estimation of Cys, $\mathrm{H}_{2} \mathrm{~S}$ content and activity of their biosynthesizing enzymes}

Quantitative analysis of Cys was carried out by the method of Gaitonde (1967). Activity Cysbiosynthesizing enzymes, $O$-acetylserine (thiol) lyase (OAS-TL; EC 2.5.1.47) and serine acetyltransferase (SAT; EC 2.2.1.30) was measured according to Riemenschneider et al. (2005a) and Nakamura et al. (1987), respectively. Quantification of $\mathrm{H}_{2} \mathrm{~S}$ was performed by the method of $\mathrm{Li}$ (2015). The activity of Lcysteine desulfhydrase (LCD; EC 4.4.1.1) and and D-cysteine desulfhydrase (DCD; EC 4.4.1.15) was estimated by the method of Bloem et al. (2004) and Riemenschneider et al. (2005b), respectively. 
Effect of drought and other treatments on oxidative stress was evaluated by estimating the level of $\mathrm{O}_{2}{ }^{--}$ and $\mathrm{H}_{2} \mathrm{O}_{2}$ according to the method of Elstner and Heupel (1976) and Velikova et al. (2000), respectively.

Effect of treatments on oxidative stress-induced damage was assessed by estimating electrolyte leakage (ELKG) according to Lutts et al. (1995) and lipid peroxidation by measuring TBARS (Cakmak and Horst 1991). The detailed method was adopted from Khan et al. (2020b). Relative water content (RWC) was also measured according to Yamasaki and Dillenburg (1999) using fresh weight, dry weight, and turgid weight of the roots (Khan et al., 2020b). Moreover, rate of water loss was also determined periodically from $1 \mathrm{~h}$ to $6 \mathrm{~h}$ as per the method explained by Khan et al. (2018).

\subsection{Antioxidant enzymes assay}

Enzyme activity of SOD (EC 1.15.1.1), POX (EC 1.11.1.7), and CAT (EC 1.11.1.6) was estimated according to Upadhyaya et al. (1985), Beauchamp and Fridovich (1971), and Cakmak and Marschner (1992), respectively. Activity of APX (EC 1.11.1.11) was measured by the method of Nakano and Asada (1981). Method of Foyer and Halliwell (1976) was used for the estimation of GR (EC 1.6.4.2) activity.

\subsection{Estimation of chlorophyll (Chl) content, activity of Chl metabolizing enzymes, and carbonic} anhydrase

Concentration of Chl content ( $\mathrm{mg} \mathrm{g}^{-1}$ leaf DW) in the leaves of treated seedlings was estimated by the method of Lichtenthaler and Buschmann (2001). The activity of $\delta$-aminolevulinic acid dehydratase ( $\delta$ ALAD) was determined according to Jain and Gadre (2004). Chlorophyllase (Chlase) activity was determined by the method of McFeeters et al. (1971) and Fang et al. (1998).

\subsection{Data analysis}

One-way analysis of variance (ANOVA) was applied for statistical analysis of the data. The values were expressed as means \pm standard error of three independent replicates. Differences between treatment means were compared statistically using Duncan's multiple range test (DMRT) at $p<0.05$ by SPSS Ver. 20 statistical software (SPSS Inc., Chicago, IL, USA)

\section{Results And Discussion}

3.1. Endogenous $K$ homeostasis and $H^{+}$-ATPase activity in tomato leaves is regulated by endogenous $\mathrm{H}_{2} \mathrm{~S}$ signaling during PEG-induced osmotic stress

Tomato seedlings ( $8 \mathrm{~d}$ old) were subjected to $15 \%(\mathrm{w} / \mathrm{v})$ PEG treatment in the presence and absence of exogenous $5 \mathrm{mM} \mathrm{K}_{2} \mathrm{CO}_{3}(\mathrm{~K})$. Osmotic stress-induced changes in endogenous $\mathrm{K}$ content coincides with the modulation of $\mathrm{H}^{+}$-ATPase activity. In the present work PEG-induced osmotic stress significantly reduces $\mathrm{K}$ 
content $(45.8 \%)$ which corresponds to a concomitant reduction in the activity of $\mathrm{H}^{+}$-ATPase $(19.1 \%)$ in comparison with their respective controls (Fig. $1 \mathrm{~A}$ and $\mathrm{B}$ ). In order to investigate the role of endogenous $\mathrm{H}_{2} \mathrm{~S}$ on the modulation of $\mathrm{K}$ content, tomato seedlings were also treated with $20 \mathrm{mM}$ TEA (K channel blocker) and $1 \mathrm{mM} \mathrm{HT}\left(\mathrm{H}_{2} \mathrm{~S}\right.$ scavenger). Although exogenous $\mathrm{K}$ treatment partially recovered PEGinduced decrease in endogenous $\mathrm{K}$ content. However, $\mathrm{HT}$ and TEA application (separate or in combination) reduced the $\mathrm{K}$ content (Fig. $1 \mathrm{~A}$ ). A similar trend of reduction in the $\mathrm{H}^{+}$-ATPase activity was observed in the presence of exogenous HT and TEA. Furthermore, treatment with sodium orthovanadate (SOV, PM H ${ }^{+}$-ATPase inhibitor) resulted in decreased $\mathrm{K}$ content in leaves of tomato seedlings treated with PEG and $\mathrm{K}$ (Fig. $2 \mathrm{~A}$ ). Treatment with TEA exhibits different trends in the levels of $\mathrm{K}$ content in the presence of PEG and PEG+K. TEA treatment increased $K$ content in the presence of PEG application (PEG) which, however, decreased in the presence of PEG+K treatment (Fig. 2 B). It indicates that TEA substantially inhibited $\mathrm{K}$ efflux in the stressed seedlings that did not receive exogenous $\mathrm{K}$. However, TEA did not significantly inhibited $K$ efflux in the stressed seedlings subjected to $K$ treatment (Fig. 1 A, 2 B). This observation indicates that under $\mathrm{K}$ supplementation, $\mathrm{H}^{+}$-ATPase activity regulates endogenous $\mathrm{K}$ content in tomato seedlings leaves subjected to osmotic stress (Fig. 1 B, 2 A).

Drought stress significantly affects ion uptake mechanisms in plants including K (Asif et al. 2017; Ahmad et al. 2018). Reduction in the leaf water potential is usually associated with an alteration in $\mathrm{K}$ content during drought stress (Gunes et al. 2007). Among the various effects of drought stress, reduced water availability in roots affects membrane permeability and reduces active transport of nutrients which are attributed to reduced levels of $\mathrm{K}$ in plant organs (Ahmad et al. 2018). Drought stress is known to promote the expression of high affinity $\mathrm{K}$ transporter (OsHAK1) in rice thus improving $\mathrm{K}$ acquisition in the plant (Chen et al. 2017). $\mathrm{K}$ homeostasis in mesophyll cells of drought stressed tea plants have been reported to be mediated by the activity of $\mathrm{H}^{+}$-ATPase (Zhang et al. 2018). In comparison with PEG treatment, endogenous $\mathrm{K}$ content exhibits $69.1 \%$ increase in the presence of PEG+K treatment which also corresponds to a $41.6 \%$ increase in the $\mathrm{H}^{+}$-ATPase activity (Fig. $1 \mathrm{~A}, \mathrm{~B}$ ). Thus, exogenous $\mathrm{K}$ supplementation during PEG-induced osmotic stress is likely to normalize $\mathrm{H}^{+}$-ATPase activity (Palmgren 2001 ) thus increasing $\mathrm{K}$ content in leaves of drought stressed tomato seedlings. $\mathrm{H}^{+}$-ATPase activity in the plasma membrane is crucial for maintaining $\mathrm{K}$ uptake which is mediated by secondary transport mechanisms ( $\mathrm{K}$ transporters or $\mathrm{H}^{+} / \mathrm{K}^{+}$symporters) (Shabala 2017; Khan et al. 2020b). In the present work, reduction in the $\mathrm{H}^{+}$-ATPase activity during PEG treatment likely results in net $\mathrm{H}^{+}$-influx and subsequent membrane depolarization. Thus, reduction in $\mathrm{K}$ content during PEG treatment might be resulting from depolarization of membrane (Wang et al. 2015) that activated K-efflux systems across the membranes. Exogenous $\mathrm{K}$ supplementation alleviated the $\mathrm{PEG}$-induced $\mathrm{K}$ loss by activating $\mathrm{H}^{+}$-ATPase activity (Palmgren 2001) in the leaves (Fig. 1 A, B). Furthermore, $\mathrm{H}^{+}$-ATPase dependent $\mathrm{K}$ accumulation was reversed upon treatment with SOV which resulted in a reduction in $\mathrm{K}$ content (Fig. $2 \mathrm{~A}$ ). Exogenous $\mathrm{K}$ induced increment in endogenous $\mathrm{K}$ content was also evident to be mediated by $\mathrm{H}^{+}$-ATPase activity, as shown by subsequent reduction in $\mathrm{K}$ content in the presence of SOV treatment (Fig. 2A). 
It is note-worthy that treatment with $\mathrm{HT}$ (endogenous $\mathrm{H}_{2} \mathrm{~S}$ scavenger) resulted in a reduction in the endogenous $\mathrm{K}$ content (19.5\%) and $\mathrm{H}^{+}$-ATPase activity (42.1\%) in comparison with the stressed seedlings treated with $\mathrm{K}$ only $(\mathrm{PEG}+\mathrm{K})$ (Fig. $1 \mathrm{~A}, \mathrm{~B}$ ). Thus, $\mathrm{H}^{+}$-ATPase dependent modulation of $\mathrm{K}$ content during osmotic stress is evident to be operative through endogenous $\mathrm{H}_{2} \mathrm{~S}$ signaling. Reduction in endogenous $\mathrm{H}_{2} \mathrm{~S}$ content brought about by $\mathrm{HT}$ treatment down regulates $\mathrm{H}^{+}$-ATPase activity and reduces $\mathrm{K}$ content as a downstream signaling event. It is evident that $\mathrm{H}_{2} \mathrm{~S}$ treatment exerts promotive effects manifested by the upregulation of gene expression and phosphorylation of plasma membrane associated $\mathrm{H}^{+}$-ATPase activity in Arabidopsis (Li et al. 2014). The increase in $\mathrm{K}$ content due to $\mathrm{H}_{2} \mathrm{~S}$ signaling is attributed to the upregulation of $\mathrm{Na} / \mathrm{K}$ antiport system being energized by the activity of $\mathrm{H}^{+}$-ATPase (Khan et al., $2020 \mathrm{~b}$ ). $\mathrm{H}_{2} \mathrm{~S}$ is a positive regulator of $\mathrm{K}$ retention and mediates ion homeostasis during salinity stress (Mostofa et al. 2015; Deng et al. 2016). The present evidence reveal that endogenous $\mathrm{H}_{2} \mathrm{~S}$ modulates $\mathrm{H}^{+}$-ATPase dependent-K content in leaves of stressed tomato seedlings. Furthermore, exogenous K-mediated alleviation of induced osmotic stress and partial recovery in endogenous $K$ content is also mediated by the endogenous $\mathrm{H}_{2} \mathrm{~S}$ (Fig. 10).

\section{2. $\mathrm{K}$ and endogenous $\mathrm{H}_{2} \mathrm{~S}$ exert additive effects in modulating sugar metabolism during osmotic stress}

Exogenous $\mathrm{K}$ treatment led to an increase in starch (13.3\%) and sucrose (66.4\%) content in tomato seedling leaves in comparison with their control (Fig. 3 A, B). However, osmotic stress being induced by PEG treatment resulted in decreased starch content accompanied by increase in sucrose level (Fig. 3 A, B). Exogenous K supplementation to PEG treatment compensates PEG-induced reduction in starch content also followed by a reduction in sucrose content. However, HT and TEA treatment reduce both starch and sucrose content in comparison with their controls. Total soluble sugars (TSS) exhibit marginal increase in the presence of $\mathrm{K}$ which, however, decreases during osmotic stress induced by PEG treatment (46.8\%). Treatments with HT and TEA reversed the effect of K-mediated increase in TSS content during osmotic stress. Changes in starch and sucrose content correlate with variations in the activity of enzymes associated with starch hydrolysis (a-amylase, $\beta$-amylase), sucrose biosynthesis (SPS), and sucrose hydrolysis (SuSy and SAI) (Fig. 4 A-E). Apart from its role as a storage molecule, starch level is known to exhibit dynamic changes during abiotic stress thus indicating its involvement in metabolic fitness of plants (Thalmann and Santelia 2017). Starch degradation during abiotic stress is associated with improved osmotic tolerance attained by higher sugar accumulation. Drought resistant variety of broad bean (Phaseolus vulgaris) has been reported to undergo higher starch breakdown in comparison with the sensitive strains (González-Cruz and Pastenes 2012). Starch hydrolysing enzymes (a-amylase, $\beta$-amylase) undergo upregulation in the presence of $\mathrm{K}+\mathrm{PEG}$ treatment which also get reduced upon HT and TEA treatment. Similar trend was observed for the enzymes associated with sucrose metabolism. Thus, $\mathrm{K}$ and endogenous $\mathrm{H}_{2} \mathrm{~S}$ appear to positively upregulate carbohydrate metabolism in drought stressed tomato leaves (Fig. 10).

Source tissues like leaves undergo a precise control of starch-sugar inter-conversion during abiotic stress signals (Thitisaksakul et al. 2017; Thalmann and Santelia 2017). PEG-induced osmotic stress in tomato 
leaves results in decreased starch content (18.3\%) in comparison with the control (Fig. 3A). However, in the presence of $\mathrm{K}$ and $\mathrm{K}+\mathrm{PEG}$ treatment a recovery in the starch content has been observed (Fig. $3 \mathrm{~A}$ ). Interestingly, higher endogenous K content (Fig. 1A) correlates with higher retention of starch during PEGinduced osmotic stress. K concentrations are likely to improve the osmotic potential of cells thus compensating the need of higher osmolyte accumulation (Fig. 10). Increased degradation of starch in osmotic-stressed tomato leaves coincides with higher sucrose accumulation (Fig. 3B). A surge in starch catabolism is observed during PEG-induced osmotic stress and exogenous $\mathrm{K}$ application which is evident by the increased activity of a-amylase and $\beta$-amylase in tomato leaves (Fig. 4 A, B). K appears to be a positive regulator of $\alpha$-amylase and $\beta$-amylase enzymes (Hasanuzzaman et al. 2018) thus upregulating their activity in the presence of PEG-induced osmotic stress (Fig. 10). Water stress in cucumber cotyledons is known to induce starch degradation which is associated with increased $\beta$-amylase activity (Todaka et al. 2000). In the present work, increased activity of a-amylase and $\beta$-amylase enzymes corroborate the fact that PEG-induced sucrose accumulation possibly results from increased starch degradation. Leaves are the primary source organs which accumulate sucrose and starch as the major forms of photosynthates. However, K application during osmotic stress (PEG) exert differential effects to starch and sucrose content (Fig. 3A and B). However, total soluble sugar (TSS) content exhibits a reduction in the presence of PEG (40.3\%) which, however, is increased upon K supplementation (Fig. 3 C). Interestingly, reduced TSS content in tomato leaves (Fig. $3 \mathrm{C}$ ) is likely attributed to increased long distance transport of solutes from leaves to other plant organs during osmotic stress (Cramer et al. 2007). Source-sink relations involve precise modulation in the mobilization of sugar assimilates during drought stress (Lemoine et al. 2013). Increased K content (exogenous) partially compensates the effect of osmotic stress that might result in a higher retention of TSS in leaves (Fig. 3 C).

Sucrose metabolism during osmotic stress and $\mathrm{K}$ supplementation has been analyzed by investigations on the activity of sucrose phosphate synthase (SPS), sucrose synthase (SuSy) and soluble acid invertase (SAI) activity (Fig. 4 C, D, E). Interestingly, SPS and SuSy/SAl activity exhibit opposite trends in the presence of K and PEG treatments. K and PEG treatment resulted in $11.6 \%$ and $35.0 \%$ increment in SPS activity respectively which all the more increased $65.0 \%$ in the presence of PEG+K treatment as compared with control (Fig. $4 \mathrm{C}$ ). This signifies the role of $\mathrm{K}$ and PEG in upregulating sucrose biosynthesis catalysed by the activity of SPS. SuSy activity exhibits $43.9 \%$ increase in the presence of $\mathrm{K}$ treatment, which, however, decreases by $26.5 \%$ in the presence of PEG as compared with the control (Fig. 4 D). However, K supplementation of stressed seedlings (K+PEG) improved SuSy activity by $63.0 \%$ than the stressed seedlings raised without $K$ supply (PEG). Increased endogenous $K$ content promotes sucrose hydrolysis in tomato leaves which is evident from increased SuSy and SAI activity. Higher accumulation of sucrose in PEG-treated tomato leaves corresponds with reduced sucrose hydrolysis (SuSy/SAl activity) and increased sucrose biosynthesis (SPS activity) (Fig. 3B, Fig. 4 C, D, E). Although various sucrose cleaving enzymes act differently during abiotic stress, SuSY and SAl activity during drought stress pertains to higher accumulation of hexose sugars (Pinheiro et al. 2001; Praxedes et al. 2006). Drought stress is known to enhance sugar metabolism by increasing the activity of SPS and SuSy in roots of soybean 
seedlings (Du et al. 2020). K application has been known to upregulate sugar metabolism by enhancing the activity of SPS, SuSy and SAl in water stressed cotton plants (Zahoor et al. 2017b).

Interestingly, in the present work, HT and TEA treatment reduced starch, sucrose and TSS content (Fig. 3 A-C) followed by down-regulation in the activity of starch and sucrose metabolizing enzymes (Fig. 4 A-E). Fewer reports are present to elucidate the regulatory role of $\mathrm{H}_{2} \mathrm{~S}$ in modulation of carbohydrate metabolism during drought stress. Proteomic analysis by Jiang et al. (2020) deciphers the role of $\mathrm{H}_{2} \mathrm{~S}$ in regulating various enzymes associated with carbohydrate metabolism in salt-stressed cucumber leaves. Present findings reveal that $\mathrm{K}$ and endogenous $\mathrm{H}_{2} \mathrm{~S}$ appear to exert additive effects in the positive regulation of carbohydrate metabolism in leaves of osmotic-stressed tomato seedlings (Fig. 10).

\section{3. $\mathrm{K}$ regulates endogenous $\mathrm{H}_{2}$ S homeostasis during osmotic stress in tomato leaves}

Cysteine functions as the major precursor for $\mathrm{H}_{2} \mathrm{~S}$ biosynthesis in plant cells where the reaction is catalyzed by the activity of cysteine desulfhydrases (LCD or DCD). In order to investigate the possible role of $\mathrm{K}$ in regulating endogenous $\mathrm{Cys}$ and $\mathrm{H}_{2} \mathrm{~S}$ biosynthesis, drought stressed tomato leaves were subjected to enzymatic assay for SAT, OASTL, LCD and DCD. PEG-induced osmotic stress upregulated SAT and OASTL activity which all the more increased in the presence of $K$ supplementation ( $K+P E G)$ (Fig. 5 A-B). A similar trend was observed in the activity of LCD and DCD under PEG induced stress (Fig. 6 A) The increase in activity of the enzymes correlates with increased Cys and $\mathrm{H}_{2} \mathrm{~S}$ content in the presence of $\mathrm{K}$ and PEG treatment (Fig. $5 \mathrm{C}, 6 \mathrm{~B}$ ). It is noteworthy that PEG-induced osmotic stress upregulated $\mathrm{H}_{2} \mathrm{~S}$ biosynthesis in leaves of tomato seedlings. L-cysteine desulhydrase (LCD) activity was observed to be more abundant in comparison with D-cysteine desulfhydrase activity (DCD) in leaves of tomato seedlings (Fig. 6 A, B). However, both the enzymes showed upregulation in the presence of $K$ and PEG treatment. Interestingly, $\mathrm{HT}$ and TEA treatment downregulated both Cys and $\mathrm{H}_{2} \mathrm{~S}$ biosynthesis during PEG-induced osmotic stress in tomato leaves (Fig. 5A-C; Fig. 6 A and B). It is noteworthy that PEG-induced osmotic stress upregulated $\mathrm{H}_{2} \mathrm{~S}$ biosynthesis in leaves of tomato seedlings. L-cysteine desulhydrase (LCD) activity was observed to be more abundant in comparison with D-cysteine desulfhydrase activity (DCD) in leaves of tomato seedlings (Fig. 6 A, B). However, both the enzymes showed upregulation in the presence of $\mathrm{K}$ and PEG treatment.

Exogenous $\mathrm{H}_{2} \mathrm{~S}$ is known to upregulate both Cys and $\mathrm{H}_{2} \mathrm{~S}$ biosynthesis during water deficit in Eruca sativa (Khan et al. 2018). The activity of OASTL, LCD, and DCD were reported to be upregulated in the presence of exogenous NaHS ( $\mathrm{H}_{2} \mathrm{~S}$ donor) where a surge in Cys and $\mathrm{H}_{2} \mathrm{~S}$ accumulation was observed (Khan et al. 2018). OASTL and LCD function as crucial enzymes for Cys homeostasis in Arabidopsis (Álvarez et al. 2010). Recent investigations reveal the role of LCD and $\mathrm{H}_{2} \mathrm{~S}$ homeostasis to be associated with salinity tolerance and regulation of electrolytic leakage in Zea mays and Solanum lycoperscicum (Kaya et al. 2019; Mukherjee and Bhatla 2020). Among the various roles of LCD and $\mathrm{H}_{2} \mathrm{~S}$ during abiotic stress, they are known to be associated with the evocation of glutathione-mediated antioxidative defense, hormonal signaling and silicon-induced signaling (Kaya et al. 2020a, b, c; Mukherjee and Corpas 2020). In 
the present work in tomato leaves $\mathrm{H}_{2} \mathrm{~S}$ content has been observed to steadily increase as a function of both LCD and DCD activity (Fig. 6B). Tissue levels of $\mathrm{H}_{2} \mathrm{~S}$ as a signaling molecule has been reported to be increased up to 2.5-fold in response to various biotic and abiotic stress (Fang et al. 2014; Khan et al. 2020a). Upregulation of $L C D / D C D$ activity and associated $\mathrm{H}_{2} \mathrm{~S}$ levels are suggestive of their possible role in ROS homeostasis and drought stress tolerance (Kaya et al. 2020a, b). Recent evidence has provided significant insights to the antioxidative role of $\mathrm{H}_{2} \mathrm{~S}$ as a priming and anti-senescence molecule for alleviation of drought and heavy metal stress in plants (Jin et al. 2018; Khan et al. 2020a; Zhou et al. 2020). Leaves of tomato seedlings subjected to drought stress exhibit higher accumulation of $\mathrm{H}_{2} \mathrm{~S}$ (Fig. 6 B) which is possibly attributed to its downstream functional regulation of redox homeostasis and senescence control during drought stress. Present findings therefore reveal that $\mathrm{H}_{2} \mathrm{~S}$ homeostasis is crucially regulated by $\mathrm{K}$, endogenous Cys metabolism, and $\mathrm{H}_{2}$ S levels during PEG-induced osmotic stress in tomato leaves (Fig. 10).

\section{4. $\mathrm{K}$ and $\mathrm{H}_{2} \mathrm{~S}$ modulate ROS homeostasis and enzymatic antioxidative defense in osmotic stressed- tomato leaves}

Drought stress (PEG) in tomato seedling leaves resulted in increased $\mathrm{O}_{2}{ }^{\cdot-}$ and $\mathrm{H}_{2} \mathrm{O}_{2}$ content which was, however, observed to be depleted during PEG+K treatment (Fig. $7 \mathrm{~A}$ and B). Furthermore, exogenous Kmediated decrease in ROS levels undergo surge in the presence of HT and TEA treatments. The increased ROS levels in the presence of PEG, HT, and TEA correlate to modulation in the activity of antioxidative enzymes (SOD, POX, CAT, APX and GR) (Fig. 9 A-D). Osmotic stress induced by PEG treatment leads to a significant increase in $\mathrm{H}_{2} \mathrm{O}_{2}$ and $\mathrm{O}_{2}{ }^{\cdot-}$ content in comparison with their control (Fig. 7A and B) (Khan et al. 2017; Liu et al. 2019). However, exogenous $\mathrm{K}$ compensates the impact of drought stress, thus reducing the levels of free radical generation. Although the treatments with HT and TEA (separately) increased the levels of ROS, their treatment in combination ( $\mathrm{K}+\mathrm{PEG}+\mathrm{HT}+\mathrm{TEA}$ ) led to a note-worthy increase in $\mathrm{O}_{2}{ }^{\cdot-}$ and $\mathrm{H}_{2} \mathrm{O}_{2}$ levels in tomato leaves. Osmotic stress in tomato leaves resulted in increased lipid peroxidation (TBARS) which all the more increases in the presence of TEA and HT in combination (Fig. $7 \mathrm{C}$ ). Thus, the extent of lipid peroxidation during osmotic stress correlates with the increased levels of $\mathrm{O}_{2}{ }^{-{ }^{-}}$and $\mathrm{H}_{2} \mathrm{O}_{2}$ generated during PEG-induced osmotic stress. Furthermore, interesting correlations are obtained among endogenous K (Fig. 1A), $\mathrm{H}_{2}$ S level (Fig. 6 B) and ROS generation during PEG-induced osmotic stress. High levels of ROS generated during TEA and HT treatment signify the beneficial role of $\mathrm{K}$ and $\mathrm{H}_{2} \mathrm{~S}$ in regulating ROS levels during osmotic stress. Various investigations reveal the beneficial role of $\mathrm{H}_{2} \mathrm{~S}$ signaling in regulating the antioxidant state during drought and other abiotic stress (Ahmad et al. 2020b; $\mathrm{K}$ han et al. 2017, 2020a, b). Present work reveals $\mathrm{K}$ and endogenous $\mathrm{H}_{2} \mathrm{~S}$-mediated regulation of antioxidative enzymes during osmotic stress in tomato leaves (Fig. 9 A-D). Osmotic stress (PEG) upregulates the activity of SOD, POX, CAT, APX and GR, which, however, gets reduced in the presence of $\mathrm{HT}$ and TEA treatment. Thus, endogenous $\mathrm{K}$ and $\mathrm{H}_{2} \mathrm{~S}$ positively upregulate the activity of the antioxidative enzymes. SOD catalyzes the dismutation of superoxide ions to form $\mathrm{H}_{2} \mathrm{O}_{2}$. Potassium supplementation during drought stress reduces superoxide levels (Fig. 7 B) which correspond to the 
higher activity of SOD (Fig. 9 A). Furthermore, PEG, $\mathrm{K}$ and $\mathrm{H}_{2}$ S-mediated changes in $\mathrm{H}_{2} \mathrm{O}_{2}$ levels exhibit inverse correlation with POX, CAT, and APX activity (Fig. 9 A and B). Interestingly, all the antioxidative enzymes analyzed in the present work (SOD, POX, CAT, APX and GR) exhibit highest activity in the presence of PEG+K treatment, which, however, gets reduced in the presence of HT and TEA (Fig. 9 A-D). Thus, K-mediated alleviation of osmotic stress accompanies a surge in the $\mathrm{H}_{2} \mathrm{~S}$ biosynthesis and mediates a $\mathrm{H}_{2} \mathrm{~S}$-dependent induction of antioxidative defense. $\mathrm{H}_{2} \mathrm{~S}$ is known to modulate the activity of SOD, CAT, POD, APX and GR in plants subjected to abiotic stress (Ahmad et al. 2020b; Khan et al. 2017; Khan et al. 2020a, b), wherein $\mathrm{H}_{2} \mathrm{~S}$ also functions as an important regulator of glutathione-ascorbate cycle (Kaya et al. 2020a; Khan et al. 2018, 2020a, b). Glutathione reductase catalyzes the conversion of GSSG into GSH which is crucial in maintaining tolerance to oxidative stress. Present work reveals an elevation in GR activity (PEG+K) (Fig. 9D) thus signifying higher accumulation of GSH in leaves of drought stressed tomato seedlings. Enhanced levels of GSH along with $\mathrm{H}_{2} \mathrm{~S}$ has been reported to be effective in imparting tolerance to oxidative stress (Kaya et al. 2020a; Khan et al. 2018, 2020a, b). Our findings are indicative of the fact that endogenous $\mathrm{K}$ functions as a positive regulator of $\mathrm{H}_{2} \mathrm{~S}$-mediated antioxidative defense against osmotic stress (Fig. 10).

\section{5. $\mathrm{K}$ mediated- $\mathrm{H}_{2} \mathrm{~S}$ signaling reduces osmotic stress and leaf water loss}

Analysis of relative water content (RWC) and electrolytic leakage (ELKG) in osmotic-stressed tomato leaves reveal variations associated with PEG, HT, and TEA treatment. Osmotic stress (PEG) increases ELKG followed by reduced RWC (Fig. 8 A) in tomato leaves. Electrolytic leakage from the osmoticstressed leaves is further enhanced in the presence of HT and TEA treatment (Fig. 8A). Increased ELKG correlates with reduced RWC in the presence of PEG and HT/TEA treatment in tomato leave (Fig. 8A). Exogenous $\mathrm{K}$ appears beneficial in alleviating the effect of osmotic stress by causing increase in RWC and subsequent reduction in EKLG. Furthermore, $\mathrm{HT}$ treatment reveals the role of endogenous $\mathrm{H}_{2} \mathrm{~S}$ in regulation of ELKG. Leaf water loss exhibits increase in the presence of PEG, $H T$, and TEA treatment with maximum increase at $6 \mathrm{~h}$ after osmotic stress (Fig. $8 \mathrm{~B}$ ).

Membrane permeability and ion homeostasis are crucial for imparting osmotic tolerance to plants. Drought stress in general reduces RWC in plant tissues (Khan et al. 2017, 2018; Chen et al. 2016). $\mathrm{H}_{2} \mathrm{~S}$ exerts beneficial role in increasing RWC accompanied by increase in osmoprotectants in Spinacia seedlings (Chen et al., 2016). In the present work, $\mathrm{K}$ and $\mathrm{H}_{2} \mathrm{~S}$ upregulate osmotic tolerance (RWC, sucrose content) in a synergistic manner (Fig. 3B, Fig. 8 A). Furthermore, analysis of leaf water loss in the presence of $\mathrm{K}$ and $\mathrm{H}_{2} \mathrm{~S}$ treatment during osmotic stress reveals its temporal increase from 1-6h in the presence of PEG, $\mathrm{HT}$ and TEA treatment (Fig. $8 \mathrm{~B}$ ). $\mathrm{K}$ and $\mathrm{H}_{2} \mathrm{~S}$ are likely to impart beneficial role in regulating stomatal movement during drought stress which is attributed to the reduction in water loss in $\mathrm{K}$ or $\mathrm{K}+\mathrm{PEG}$ treated seedling leaves. $\mathrm{H}_{2} \mathrm{~S}$-mediated stomatal closure during water stress is attributed to the evocation of ABA biosynthesis and its signaling in guard cells (Chen et al. 2020; Zhou et al. 2020). Thus, it is advocated that $\mathrm{K}$ and $\mathrm{H}_{2} \mathrm{~S}$ signaling orchestrate osmotic tolerance, sucrose accumulation, stomatal conductance and hydroactive stomatal closure in drought stressed leaves (Fig. 10). 
3.6. $\mathrm{K}$ and $\mathrm{H}_{2} \mathrm{~S}$ regulate chlorophyll metabolism and carbonic anhydrase activity in osmotic-stressed tomato leaves

Chlorophyll metabolism (in the presence of $\mathrm{K}, \mathrm{PEG}, \mathrm{HT}$, and TEA treatments) exhibits precise regulation by endogenous $\mathrm{K}$ and $\mathrm{H}_{2} \mathrm{~S}$ in drought stressed tomato leaves. PEG treatment reduces chlorophyll content $(49.6 \%)$ of tomato leaves accompanied by reduction (32.9\%) in the activity of $\delta$-ALAD (chlorophyll precursor biosynthesizing enzyme) (Table 1) which is, however, reversed by HT and TEA treatments. Chlorophyllase activity shows upregulation in the presence of PEG which even more increases in the presence of HT and TEA (Table 1). CA activity is downregulated during osmotic stress which, however, gets recovered in the presence of PEG+K (Table 1).

Drought stress is known to reduce Chl biosynthesis in plants (Chen et al. 2015; Meher et al. 2018; Siddiqui et al. 2015). PEG-induced osmotic stress instigates ROS levels, increases lipid peroxidation (Fig. 7 A-C) which is accompanied by a significant decrease in Chl content and reduced activity of Chl-metabolizing enzymes ( $\delta$-ALAD) (Table 1). Potassium supplementation during PEG-induced osmotic stress partially recovers chl content and $\delta$-ALAD activity. Thus, delayed senescence due to $\mathrm{K}$ supplementation in osmoticstressed leaves are likely to maintain optimum photosynthesis and carbon assimilation in cells. $\delta$-ALAD activity is responsible for synthesis of $\mathrm{Chl}$ precursor in leaves. Furthermore, chl catabolizing enzyme Chlas gets increased in the presence of PEG treatment and all the more in the presence of HT and TEA (Table 1). Evidence by Jin et al. (2018) reveal $\mathrm{H}_{2} \mathrm{~S}$-mediated regulation of senescence associated gene expression and delay in senescence in drought stressed-Arabidopsis. Endogenous $\mathrm{K}$ and $\mathrm{H}_{2} \mathrm{~S}$ levels are positive regulators of $\mathrm{Chl}$ metabolism during osmotic stress in tomato leaves (Table 1).

Carbonic anhydrase (CA) activity is crucial for maintaining dissolved $\mathrm{CO}_{2}$ at the carboxylation site of RUBISCO present in mesophyll cells (Gruber and Feiz 2018). Moreover, CA activity serves as a marker for stress which responds to external environmental stimulus in plants (Khan et al. 2018). CA activity is essential to maintain calvin cycle, stomatal conductance thus enabling $\mathrm{CO}_{2}$ diffusion across guard cells. Water stress negatively affects CA activity in mesophyll cells thus causing subsequent reduction in photosynthetic assimilation (Król and Weidner 2017). Present work reveals PEG-induced reduction in the activity of $\mathrm{CA}$ which is, however, recovered by exogenous $\mathrm{K}$ supplementation (Table 1 ). Moreover, $\mathrm{K}$ appears to function as a significant positive regulator of CA activity in the presence of PEG treatment where CA activity is significantly enhanced $(70.5 \%)$ in comparison with the stressed seedlings (PEG). Endogenous $\mathrm{K}$ and $\mathrm{H}_{2} \mathrm{~S}$ positively upregulate the activity of $\mathrm{CA}$, where treatment with TEA+HT causes $68.0 \%$ reduction in CA activity than K+PEG (Table 1). CA activity is essential to protect the function of RUBISCO and regulate stomatal closure during drought stress (Gruber and Feiz 2018). Endogenous $\mathrm{K}$ and sucrose levels (present work) are likely to regulate osmotic balance in mesophyll cells of stressed tomato leaves. Thus, alleviation of osmotic stress is associated with increased CA activity which is expected to improve stomatal conductance and $\mathrm{CO}_{2}$ diffusion thus maintaining optimum carbon assimilation. In this context it is noteworthy that endogenous $\mathrm{H}_{2} \mathrm{~S}$ is crucial for maintaining optimum CA 
activity during osmotic stress. Thus, $\mathrm{K}$ and $\mathrm{H}_{2} \mathrm{~S}$-mediated drought tolerance and regulation of photosynthetic assimilation is accompanied by modulation of CA activity in tomato leaves.

3.7. $\mathrm{K}$ and $\mathrm{H}_{2} \mathrm{~S}$ signaling exhibit positive correlations in orchestration of long-distance osmotic stress tolerance in tomato leaves

A significant positive relationship is observed among endogenous $\mathrm{H}_{2} \mathrm{~S}$ content, $\mathrm{K}$ and $\mathrm{H}^{+}$-ATPase activity in the presence of PEG-induced drought stress in tomato seedling leaves (Fig. 1 A and B, Fig. 6B). Interestingly, increased $\mathrm{H}^{+}$-ATPase activity positively upregulates secondary transport of $\mathrm{K}$ in leaves which is further accompanied by increased sucrose accumulation, higher RWC and elevated starch degradation (Fig. 10). In this context exogenous supplementation of $\mathrm{K}$ appears to positively upregulates Cys and $\mathrm{H}_{2} \mathrm{~S}$ biosynthesis (SAT, OASTL, LCD, DCD) in osmotic-stressed tomato leaves. Thus, improved accumulation of sucrose is indicative of restored photosynthetic assimilation which correlates with retention of chlorophyll, $\delta$-ALAD activity and reduced Chlase activity under osmotic stress. Reduced TSS under osmotic-stressed leaves are indicative of reallocation of organic nutrients from source to sink organs. However, $\mathrm{K}$ and $\mathrm{H}_{2} \mathrm{~S}$ tend to retain TSS in the leaves of stressed tomato seedlings. A reduction in the ROS levels is observed in the presence of $\mathrm{K}$ supplementation during osmotic stress which correlates with altered activity of antioxidative enzymes. Thus, $\mathrm{K}$ transport and endogenous $\mathrm{H}_{2} \mathrm{~S}$ homeostasis associate with $\mathrm{H}^{+}$-ATPase activity to improve carbohydrate metabolism and promote tolerance to osmotic stress. To sum up, present evidence reveals the synergistic role of $\mathrm{K}$ and $\mathrm{H}_{2} \mathrm{~S}$ in regulating carbohydrate metabolism and osmotic stress tolerance (Fig. 10).

\section{Conclusions}

Results of the study show that osmotic stress-induced reduction in leaf $\mathrm{K}$ content was associated with the reduction in $\mathrm{H}^{+}$-ATPase activity. Also, osmotic stress adversely affected carbohydrate and chlorophyll metabolism in tomato seedlings. Whereas antioxidative defense system and $\mathrm{H}_{2} \mathrm{~S}$ metabolism was activated by osmotic stress. Contrastingly, generation of reactive oxygen species was enhanced with an associated increase in lipid peroxidation, rate of water loss and decreased RWC. It indicates that activated defense system of stressed plants failed to counter osmotic stress. However, exogenous application of $\mathrm{K}$ enhanced endogenous $\mathrm{K}$ content which further elevated the accumulation of soluble carbohydrates and causes activation of antioxidative defense system to a level required to counter osmotic and oxidative stress. Cumulative effect of these processes led to the osmotic adjustment and reduction in ROS generation coupled with reduced water loss, improved RWC and reduced peroxidation of lipids. Use of SOV ( $\mathrm{H}^{+}$-ATPase inhibitor) and TEA ( $\mathrm{K}$ channel blocker) indicates that increase in endogenous $\mathrm{K}$ content in $\mathrm{K}$ supplemented seedlings was carried out by $\mathrm{H}^{+}$-ATPase. Reduction in $\mathrm{H}^{+}$ATPase activity by $\mathrm{H}_{2} \mathrm{~S}$ scavenger $\mathrm{HT}$ suggests the involvement of endogenous $\mathrm{H}_{2} \mathrm{~S}$ in the activation of $\mathrm{H}^{+}$-ATPase activity that improved $\mathrm{K}$ influx mechanism as shown by increased $\mathrm{K}$ content in osmotic- 
stressed tomato seedling leaves. To sum up, present evidence provides insights into the role of $\mathrm{K}$ and $\mathrm{H}_{2} \mathrm{~S}$ signaling in modulation of osmotic stress tolerance in tomato seedlings

\section{Declarations}

\section{Acknowledgements:}

The authors extend their appreciation to the Deanship of Scientific Research at King Saud University for funding this work through Research Group No. RG-1441-438.

\section{Author contribution statement:}

M.H.S. S.M. and S.A. designed the experiments, and wrote the manuscript. , A.A.A, Q.D.A., B.M.A.M, and H.M.A participated in the experiments. Y.H., S.A. and M.H.S analyzed the data. All authors read and approved the final manuscript.

\section{Compliance with ethical standards}

\section{Conflict of interest:}

The authors declare that they have no conflict of interest.

\section{References}

Ahmad F, Singh A, Kamal A (2020a) Osmoprotective role of sugar in mitigating abiotic stress in plants. In: Roychoudhury A, Tripathi DK (eds) Protective chemical agents in the amelioration of plant abiotic stress: biochemical and molecular perspectives. John Wiley \& Sons Ltd.

Ahmad R, Ali S, Rizwan M, Dawood M, Farid M, Hussain A, Wijaya L, Alyemeni MN, Ahmad P (2020b) Hydrogen sulfide alleviates chromium stress on cauliflower by restricting its uptake and enhancing antioxidative system. Physiol Plant 168: 289-300. https://doi.org/10.1111/ppl.13001

Ahmad Z, Anjum S, Waraich EA, Ayub MA, Ahmad T, Tariq RMS, Iqbal MA (2018) Growth, physiology, and biochemical activities of plant responses with foliar potassium application under drought stress - a review. J Plant Nut 41: 1734-1743. 10.1080/01904167.2018.1459688

Álvarez C, Calo L, Romero LC, García I, Gotor C (2010) An O-acetylserine (thiol) lyase homolog with Lcysteine desulfhydrase activity regulates cysteine homeostasis in Arabidopsis. Plant Physiol 152: 656669. doi:10.1104/pp.109.147975

Anschütz U, Becker D, Shabala S (2014) Going beyond nutrition: Regulation of potassium homoeostasis as a common denominator of plant adaptive responses to environment. J Plant Physiol 171: 670-687. https://doi.org/10.1016/j.jplph.2014.01.009 
Arif Y, Hayat S, Yusuf M, Bajguz A (2020) Hydrogen sulfide: A versatile gaseous molecule in plants. Plant Physio Biochem 158: 372-384. https://doi.org/10.1016/j.plaphy.2020.11.045

Asif M, Yilmaz O, Ozturk L (2017) Potassium deficiency impedes elevated carbon dioxide-induced biomass enhancement in well watered or drought-stressed bread wheat. J Plant Nutr Soil Sci 180:474481. https://doi.org/10.1002/jpln.201600616

Beauchamp C, Fridovich I (1971) Superoxide dismutase: improved assays and an assay applicable to acrylamide gels. Anal Biochem 44: 276-287. https://doi.org/10.1016/0003-2697(71)90370-8

Bloem E, Riemenschneider A, Volker J, Papenbrock J, Schmidt A, Salac I, Haneklaus S, Schnug E (2004) Sulphur supply and infection with Pyrenopeziza brassicae influence L-cysteine desulphydrase activity in Brassica napus L. J Exp Bot 55:2305-2312

Bradford MM (1976) A rapid and sensitive method for the quantification of microgramquantities of protein utilizing the principle of protein-dye binding. Anal Biochem 72:248-254.

https://doi.org/10.1016/0003-2697(76)90527-3

Cakmak I, Horst JH (1991) Effects of aluminum on lipid peroxidation, superoxide dismutase, catalase, and peroxidase activities in root tips of soybean (G/ycine max). Physiol Plant 83:463-468.

https://doi.org/10.1111/j.1399-3054.1991.tb00121.x

Cakmak I, Marschner H (1992) Magnesium deficiency and high light intensity enhance activities of superoxide dismutase, ascorbate peroxidase, and glutathione reductase in bean leaves. Plant Physiol 98:1222-1227. https://doi.org/10.1104/pp.98.4.1222

Chen D, Wang S, Cao B, Cao D, Leng G, Li H, Yin L, Shan L, Deng X (2015) Genotypic variation in growth and physiological response to drought stress and rewatering reveals the critical role of recovery in drought adaptation in maize seedlings. Front Plant Sci 6: 1241. https://doi.org/10.3389/fpls.2015.01241.

Chen G, Liu C, Gao Z, Zhang Y, Jiang H, Zhu L, Ren D, Yu L, Xu G, Qian Q (2017) OsHAK1, a high-affinity potassium transporter, positively regulates responses to drought stress in Rice. Front Plant Sci 8:1885. doi: $10.3389 /$ fpls.2017.01885

Chen J, Shang YT, Wang WH, Chen XY, He EM, Zheng HL, Shangguan Z (2016) Hydrogen sulfide-mediated polyamines and sugar changes are involved in hydrogen sulfide-induced drought tolerance in Spinacia oleracea seedlings. Front Plant Sci 7:1173. doi: 10.3389/fpls.2016.01173

Chen SS, Jia HL, Wang XF, Shi C, Wang X, Ma PY, Wang J, Ren MJ, Li JS (2020) Hydrogen sulfide positively regulates abscisic acid signaling through persulfidation of SnRK2.6 in guard cells. Mol. Plant. 13, 732-744. https://doi.org/10.1016/j.molp.2020.01.004

Cramer, G.R., Ergul, A., Grimplet, J., Tillett, R.L., Tattersall, E.A., Bohlman, M.C., Vincent, D., Sonderegger, J., Evans, J., Osborne, C., Quilici, D., Schlauch, K.A., Schooley, D.A., Cushman, J.C., 2007. Water and salinity 
stress in grape vines: early and late changes in transcript and metabolite profiles. Funct Integr Genomics 7:111-134. doi:10.1007/s10142-006-0039-y

Darko E, Végh B, Khalil R, Marček T, Szalai G, Pál M, Janda T (2019 Metabolic responses of wheat seedlings to osmotic stress induced by various osmolytes under iso-osmotic conditions. PLoS ONE 14:e0226151. https://doi.org/10.1371/journal.pone.0226151

Deng YQ, Bao J, Yuan F, Liang X, Feng ZT, Wang BS (2016) Exogenous hydrogen sulfide alleviates salt stress in wheat seedlings by decreasing $\mathrm{Na}^{+}$content. Plant Growth Regul 79:391-399. https://doi.org/10.1007/s10725-015-0143-x

Du Y, Zhao Q, Chen L, Yao X, Zhang W, Zhang B, Xie F (2020) Effect of drought stress on sugar metabolism in leaves and roots of soybean seedlings. Plant Physiol Biochem 146: 1-12. 10.1016/j.plaphy.2019.11.003

Elstner EF, Heupel A (1976) Inhibition of nitrite formation from hydroxyl ammonium chloride., A simple assay for superoxide dismutase. Anal Biochem 70: 616-620. https://doi.org/10.1016/00032697(76)90488-7

Fang T, Cao ZY, Li JL, Shen WB, Huang LQ (2014) Auxin- induced hydrogen sulphide generation is involved in lateral root formation in tomato. Plant Physiol. Biochem 76:44-51. https://doi. org/10.1016/j.plaphy.2013.12.024

Fang Z, Bouwkamp J, Solomos T (1998) Chlorophyllase activities and chlorophyll degradation during leaf senescence in non-yellowing mutant and wild type of Phaseolus vulgaris L. J Exp Bot 49: 503-510.

Foyer $\mathrm{CH}$, Halliwell B (1976) The presence of glutathione and glutathione reductase in chloroplasts: a proposed role in ascorbic acid metabolism. Planta 133: 1-25. https://doi.org/10.1007/BF00386001

Gaitonde MK (1967) A spectrophotometric method for the direct determination of cysteine in the presence of other naturally occurring amino acids. Biochem J 104: 627-633. https://doi.org/10.1042/bj1040627

García-Morales S, Gómez-Merino FC, Trejo-Téllez FC, Tavitas-Fuentes L, Hernández-Aragón L (2018) Osmotic stress affects growth, content of chlorophyll, abscisic acid, $\mathrm{Na}^{+}$, and $\mathrm{K}^{+}$, and expression of novel NAC genes in contrasting rice cultivars. Biol Plant 62:307-317. 10.1007/s10535-017-0761-4

González-Cruz J, Pastenes C (2008) Water stress induced thermo tolerance of photosynthesis in two bean varieties (Phaseolus vulgaris L.). In: Allen JF, Gantt E, Golbeck JH, Osmond B (eds) Photosynthesis. Energy from the Sun. Springer, Dordrecht. https://doi.org/10.1007/978-1-4020-6709-9_314

Gruber VA, Feiz L (2018) Rubisco assembly in the chloroplast. Front Mol Biosci 5:24. https://doi.org/10.3389/fmolb.2018.00024. 
Gunes A, Inal A, Adak MS, Bagci EG, Cicek N, Eraslan F (2007) Effect of drought stress implemented at pre- or post- anthesis stage some physiological as screening criteria in chickpea cultivars. Russ J Plant Physiol 55:59-67. doi:10.1134/S102144370801007X

Hasanuzzaman M, Bhuyan MHMB, Nahar K, Hossain MS, Al Mahmud J, Hossen MS, Masud AAC, Moumita, Fujita M (2018) Potassium: A vital regulator of plant responses and tolerance to abiotic stresses. Agron. 8:31. doi:10.3390/agronomy8030031

Hasanuzzaman M, Bhuyan MHMB, Zulfiqar F, Raza A, Mohsin SM, Al Mahmud J, Fujita M, Fotopoulos V (2020) Reactive oxygen species and antioxidant defense in plants under abiotic stress: revisiting the crucial role of a universal defense regulator. Antioxidants 9: 681. 10.3390/antiox9080681

Hejl AM, Koster KL (2004) Juglone disrupts root plasma membrane $\mathrm{H}^{+}$-ATPase activity and impairs water uptake, root respiration, and growth in soybean (Glycine max) and corn (Zea mays). J Chem Ecol 30:453471. 10.1023/B:JOEC.0000017988.20530.d5

Hendrix S, Iven V, Eekhout T, Huybrechts M, Pecqueur I, Horemans N, Keunen E, Veylder LD, Vangronsveld $J$, Cuypers A (2020) Suppressor of gamma response 1 modulates the DNA damage response and oxidative stress response in leaves of cadmium-exposed Arabidopsis thaliana. Front Plant Sci 11:366. https://doi.org/10.3389/fpls.2020.00366

Jain M, Gadre R (2004) Inhibition of chlorophyll biosynthesis by mercury in excised etiolated maize leaf segments during greening: effect of 2-oxoglutarate. Indian $\mathrm{J}$ Exp Biol 42:419-423.

Jiang J, Ren X, Li L, Hou R, Sun W, Jiao C, Yang N, Dong Y (2020) $\mathrm{H}_{2} \mathrm{~S}$ regulation of metabolism in cucumber in response to salt-stress through transcriptome and proteome analysis. Front Plant Sci 11:1283. 10.3389/fpls.2020.01283

Jin Z, Sun L, Yang G, Pei Y (2018) Hydrogen sulfide regulates energy production to delay leaf senescence induced by drought stress in Arabidopsis. Front Plant Sci 9:1722. 10.3389/fpls.2018.01722

Kalwade SB, Devarumath RM (2013) Functional analysis of the potential enzymes involved in sugar modulation in high and low sugarcane cultivars. Appl Biochem Biotech 172:1982-1998.

Kaya C, Ashraf M, Al-Huqail AA, Alqahtani MA, Ahmad P (2020a) Silicon is dependent on hydrogen sulphide to improve boron toxicity tolerance in pepper plants by regulating the AsA-GSH cycle and glyoxalase system, Chemosphere 257:127241. https://doi.org/10.1016/j.chemosphere.2020.127241

Kaya C, Murillo-Amador B, Ashraf M (2020b) Involvement of I-cysteine desulfhydrase and hydrogen sulfide in glutathione-induced tolerance to salinity by accelerating ascorbate-glutathione cycle and glyoxalase system in Capsicum. Antioxidants 9: 603. 10.3390/antiox9070603. 
Kaya C, Sarıoğlu A, Ashraf M, Alyemeni MN, Ahmad P (2020c) Gibberellic acid-induced generation of hydrogen sulfide alleviates boron toxicity in tomato (Solanum lycopersicum L.) plants. Plant Physiol Biochem 153:53-63. https://doi.org/10.1016/j.plaphy.2020.04.038

Khan MN, AlSolami MA, Basahi RA, Siddiqui MH, Al-Huqail AA, Abbas ZK, Siddiqui ZH, Ali HM, Khan F (2020b) Nitric oxide is involved in nano-titanium dioxide-induced activation of antioxidant defense system and accumulation of osmolytes under water-deficit stress in Vicia faba L. Ecotoxicol Environ Saf 190:110152. https://doi.org/10.1016/j.ecoenv.2019.110152

Khan MN, AlZuaibr FM, Al-Huqail AA, Siddiqui MH, Ali HM, Al-Muwayhi MA, Al-Haque HN (2018) Hydrogen sulfide-mediated activation of $O$-acetylserine (thiol) lyase and L/D-cysteine desulfhydrase enhance dehydration tolerance in Eruca sativa Mill. Int J Mol Sci 19:3981. https://doi.org/10.3390/ijms19123981.

Khan MN, Mobin M, Abbas ZK, Siddiqui MH (2017) Nitric oxide-induced synthesis of hydrogen sulfide alleviates osmotic stress in wheat seedlings through sustaining antioxidant enzymes, osmolyte accumulation and cysteine homeostasis. Nitric Oxide 68:91-102.

https://doi.org/10.1016/j.niox.2017.01.001

Khan MN, Siddiqui MH, AlSolami MA, Alamri S, Hu Y, Ali HM, Al-Amri AA, Alsubaie QD, Al-Munqedhi BMA, Al-Ghamdi A (2020a) Crosstalk of hydrogen sulfide and nitric oxide requires calcium to mitigate impaired photosynthesis under cadmium stress by activating defense mechanisms in Vigna radiata. Plant Physiol Biochem 156:278-290. https://doi.org/10.1016/j.plaphy.2020.09.017

Khan MN, Siddiqui MH, Mukherjee S, Alamri S, Al-Amri AA, Alsubaie QD, Al-Munqedhi BMA, Ali HM (2020b) Calcium-hydrogen sulfide crosstalk during $\mathrm{K}^{+}$-deficient $\mathrm{NaCl}$ stress operates through regulation of $\mathrm{Na}^{+} / \mathrm{H}^{+}$antiport and antioxidative defense system in mung bean roots. Plant Physiol Biochem 159:211-225. https://doi.org/10.1016/j.plaphy.2020.11.055

Kim TH, Böhmer M, Hu H, Nishimura N, Schroeder JI (2010) Guard cell signal transduction network: Advances in understanding abscisic acid, $\mathrm{CO}_{2}$, and $\mathrm{Ca}^{2+}$ signaling. Annu Rev Plant Biol 61:561-591.

Król A, Weidner S (2017) Changes in the proteome of grapevine leaves (Vitisvinifera L.) during long-term drought stress. J Plant Physiol 211:114- 126. https://doi.org/10.1016/j.jplph.2016.11.016

Kuai J, Liu Z, Wan Y, Meng Y, Chen B, Zhao W, Zhou Z, Oosterhuis DM (2014) Waterlogging during flowering and boll forming stages affects sucrose metabolism in the leaves subtending the cotton boll and its relationship with boll weight. with boll weight. Plant Sci 223:79-98.

https://doi.org/10.1016/j.plantsci.2014.03.010.

Lemoine R, La Camera S, Atanassova R et al. (2013) Source to sink transport of sugar and regulation by environmental factors. Front Plant Sci 4:272. 10.3389/fpls.2013.00272 
Li J, Jia H,Wang J, Cao Q, Wen Z (2014) Hydrogen sulphide is involved in maintaining ion homeostasis via regulating plasma membrane $\mathrm{Na}^{+} / \mathrm{H}^{+}$antiporter system in the hydrogen peroxide-dependent manner in salt-stressed Arabidopsis thaliana root. Protoplasma 251:899-912.doi:10.1007/s00709-013-0592-x

Li X, Jiang H, Liu F, Cai J, Dai T, Cao W, Jiang D (2013) Induction of chilling tolerance in wheat during germination by pre-soaking seed with nitric oxide and gibberellin. Plant Growth Regul 71:31-40. https://doi.org/10.1007/s10725013-9805-8.

Li ZG (2015) Quantification of hydrogen sulfide concentration using methylene blue and 5, 5-dithiobis (2Nitrobenzoic Acid) methods in plants. Methods Enzymol 554:101-110.

https://doi.org/10.1016/bs.mie.2014.11.031

Lichtenthaler HK, Buschmann C (2001) Chlorophylls and carotenoids: measurement and characterization by UV- vis spectroscopy. In: Wrolstad RE, Acree TE, An H, Decker EA, Penner MH, Reid DS, Schwartz SJ, Shoemaker CF, Sporns P (eds.) Current Protocols in food analytical chemistry (CPFA), vol. 3. John Wiley and Sons, New York, NY, USA F4, 1-F4.3.8.

Liu J, Hasanuzzaman M, Wen H, Zhang J, Peng T, Sun H, Zhao Q (2019) High temperature and drought stress cause abscisic acid and reactive oxygen species accumulation and suppress seed germination growth in rice. Protoplasma 256:1217-1227. https://doi.org/10.1007/s00709-019-01354-6

Liu ZG, Guo YK, Bai JG (2010) Exogenous hydrogen peroxide changes antioxidant enzyme activity and protects ultrastructure in leaves of two cucumber ecotypes under osmotic stress. J Plant Growth Regul 29:171-183. 10.1007/s00344-009-9121-8

Lutts S, Kinet JM, Bouharmont $\mathrm{J}$ (1995) Changes in plant response to $\mathrm{NaCl}$ during development of rice (Oryza sativa $\mathrm{L}$ ) varieties differing in salinity resistance. J Exp Bot 46: 1843-1852. https://doi.org/10.1093/jxb/46.12.1843

Majumdar A, Kar RK (2018) Congruence between PM H+-ATPase and NADPH oxidase during root growth: a necessary probability. Protoplasma 255:1129-1137. 10.1007/s00709-018-1217-1

Marschner H (1995) Mineral nutrition of higher plants. 2nd ed. London: Academic Press.

McFeeters RF, Chichester CO, Whitaker JR (1971) Purification and properties of chlorophyllase from Ailanthus altissima (tree-of-heaven). Plant Physiol 47:609-618.

Meher SP, Reddy AK, Rao MD (2018) Effect of PEG-6000 imposed drought stress on RNA content, relative water content (RWC), and chlorophyll content in peanut leaves and roots. Saudi J Biol Sci 25:285-289. https://doi.org/10.1016/j.sjbs.2017.04.008 
Mehler AH (1951) Studies on reactions of illuminated chloroplasts. I. Mechanisms of the reduction of oxygen and other Hill reagents. Arch Biochem Biophys 33:65-77. 10.1016/0003-9861(51)90082-3

Mostofa MG, Saegusa D, Fujita M, Tran LS (2015) Hydrogen sulfide regulates salt tolerance in rice by maintaining $\mathrm{Na}^{+} / \mathrm{K}^{+}$balance, mineral homeostasis and oxidative metabolism under excessive salt stress. Front Plant Sci 6:1055. 10.3389/fpls.2015.01055

Mukherjee S, Bhatla SC (2020) Exogenous melatonin modulates endogenous $\mathrm{H}_{2} \mathrm{~S}$ homeostasis and Lcysteine desulfhydrase activity in salt-stressed tomato (Solanum lycopersicum L. var. cherry) seedling cotyledons. J Plant Growth Regul https://doi.org/10.1007/s00344-020-10261-7

Mukherjee S, Corpas FJ (2020) Crosstalk among hydrogen sulfide $\left(\mathrm{H}_{2} \mathrm{~S}\right)$, nitric oxide (NO) and carbon monoxide (CO) in root-system development and its rhizosphere interactions: A gaseous interactome. Plant Physiol Biochem 155: 800-814. https://doi.org/10.1016/j.plaphy.2020.08.020

Nakamura K, Hayama A, Masada M, Fukushima K, Tamura G (1987) Measurement of serine acetyltransferase activity in crude plant extracts by a coupled assay system using cysteine synthase. Plant Cell Physiol 28:885-891

Nakano G. Asada K (1981) Hydrogen peroxide is scavenged by ascorbate-specific peroxidase in spinach chloroplasts. Plant Cell Physiol 22:867-880. https://doi.org/10.1093/oxfordjournals.pcp.a076232

Palmgren M (2001) Plant plasma membrane $\mathrm{H}^{+}$-ATPase : powerhouse for nutrient uptake. Annu Rev Plant Physiol Mol Biol 52:817-845

Pinheiro C, Chaves MM, Ricardo CP (2001) Alterations in carbon and nitrogen metabolism induced by water deficit in the stems and leaves of Lupinus albus L. J Exp Bot 52:1063-1070. https://doi.org/10.1093/jexbot/52.358.1063

Praxedes SC, DaMatta FM, Loureiro ME, Ferrao MA, Cordeiro AT (2006) Effects of long-term soil drought on photosynthesis and carbohydrate metabolism in mature robusta coffee (Coffeacanephora Pierre var. kouillou) leaves. Environ Exp Bot 56:263-273. https://doi.org/10.1016/j.envexpbot.2005.02.008.

Riemenschneider A, Riedel K, Hoefgen R, Papenbrock J, Hesse H (2005a) Impact of reduced OAcetylserine(thiol)lyase isoform contents on potato plant metabolism. Plant Physiol 137:892-900. https://doi.org/10.1104/pp.104.057125

Riemenschneider A, Wegele R, Schmidt A, Papenbrock I (2005b) Isolation and characterization of a Dcysteine desulfhydrase protein from Arabidopsis thaliana. FEBS J 272:1291-1304. https://doi.org/10.1111/j.1742-4658.2005.04567.x

Sami F, Yusuf M, Faizan M, Faraz A, Hayat S (2016) Role of sugars under abiotic stress. Plant Physiol Biochem 109:54-61. 
Shabala S (2017) Signalling by potassium: another second messenger to add to the list? J Exp Bot 68:4003-4007. 10.1093/jxb/erx238

Shabala S, Cuin TA (2008) Potassium transport and plant salt tolerance. Physiol Plant 133:651-669. 10.1111/j.1399-3054.2007.01008.x

Siddiqui MH, Alamri S, Khan MN, Corpas FJ, Al-Amri AA, Alsubaie QD, Ali HM, Kalaji HM, Ahmad P (2020) Melatonin and calcium function synergistically to promote the resilience through ROS metabolism under arsenic-induced stress. J Hazard Mater 398:122882. https://doi.org/10.1016/j.jhazmat.2020.122882.

Siddiqui MH, Al-Khaishany MY, Al-Qutami MA, Al-Whaibi MH, Grover A, Ali HM, Al-Wahibi MS, Bukhari NA (2015) Response of different genotypes of faba bean plant to drought stress. Int J Mol Sci 16:1021410227. https://doi. org/10.3390/ijms160510214.

Thalmann M, Santelia D (2017) Starch as a determinant of plant fitness under abiotic stress. New Phytol 214:943-951. 10.1111/nph.14491

Thitisaksakul M, Arias MC, Dong SY, Beckles DM, (2017) Overexpression of GSK3-like Kinase 5 (OsGSK5) in rice (Oryza sativa) enhances salinity tolerance in part via preferential carbon allocation to root starch. Funct Plant Biol 44:705-719. 10.1071/FP16424

Todaka D, Matsushima H, Morohashi Y (2000) Water stress enhances beta-amylase activity in cucumber cotyledons. J. Exp Bot 51:739-745. 10.1093/jexbot/51.345.739

Upadhyaya A, Sankhla D, Davis TD, Sankhla N, Smith BN (1985) Effect of paclobutrazol on the activities of some enzymes of activated oxygen metabolism and lipid peroxidation in senescing soybean leaves. $\mathrm{J}$ Plant Physiol 121:453-461. https://doi.org/10.1016/S0176-1617(85)80081-X

Velikova V, Yordanov I, Edreva A (2000) Oxidative stress and some antioxidant systems in acid raintreated bean plants: protective role of exogenous polyamines. Plant Sci 151:59-66. https://doi.org/10.1016/S0168-9452(99)00197-1

Wang ZY, Gehring C, Zhu J, Li FM, Zhu JK, Xiong L (2015) The Arabidopsis vacuolar sorting receptor1 is required for osmotic stress-induced abscisic acid biosynthesis ${ }^{1[\mathrm{OPEN}]}$. Plant Physiol 167:137-152. doi: www.plantphysiol.org/cgi/doi/10.1104/pp.114.249268

Xu W, Cui K, Xu A, Nie L, Huang J, Peng S (2015) Drought stress condition increases root to shoot ratio via alteration of carbohydrate partitioning and enzymatic activity in rice seedlings. Acta Physiol Plant 37:9. https://doi.org/10.1007/s11738014-1760-0.

Yamasaki S, Dillenburg LC (1999) Measurements of leaf relative water content in Araucaria angustifolia. Rev Bras Fisiol Vegetal 11:69-75. 
Zahoor R, Dong H, Abid M, Zhao W, Wang Y, Zhou Z (2017a) Potassium fertilizer improves drought stress alleviation potential in cotton by enhancing photosynthesis and carbohydrate metabolism. Environ Exp Bot 137:73 83. https://doi.org/10.1016/j.envexpbot.2017.02.002

Zahoor R, Zhao W, Abid M, Dong H, Zhou Z (2017b) Potassium application regulates nitrogen metabolism and osmotic adjustment in cotton (Gossypium hirsutum L.) functional leaf under drought stress. J Plant Physiol 215:30-38.

Zhang XC, Wu HH, Chen LM, Liu LL,Wan XC (2018) Maintenance of mesophyll potassium and regulation of plasma membrane $\mathrm{H}+-$ ATPase are associated with physiological responses of tea plants to drought and subsequent rehydration. Crop J 6:611-620. https://doi.org/10.1016/j.cj.2018.06.001

Zhao N, Zhu H, Zhang H et al (2018) Hydrogen sulfide mediates $\mathrm{K}^{+}$and $\mathrm{Na}^{+}$homeostasis in the roots of salt-resistant and salt-sensitive poplar species subjected to $\mathrm{NaCl}$ stress. Front Plant Sci 9:1366. doi: $10.3389 /$ fpls.2018.01366

Zhou H, Chen Y, Zhai F, Zhang J, Zhang F, Yuan X, Xie Y (2020) Hydrogen sulfde promotes rice drought tolerance via re-establishing redox homeostasis and activation of ABA biosynthesis and signaling. Plant Physiol Biochem 156:213-220. https://doi. org/10.1016/j.plaphy.2020.07.038

\section{Table}

Table 1. Effect of various treatments on chlorophyll metabolism and carbonic anhydrase activity in the leaves of tomato. Chlorophyll (Chl) content ( $\left.\mathrm{mg} \mathrm{g}^{-1} \mathrm{DW}\right), \delta$-aminolevulinic acid dehydratase ( $\delta$-ALAD) activity (Units $\mathrm{g}^{-1} \mathrm{DW}$ ), chlorophyllase (Chlase) activity ( $\mathrm{n} \mathrm{mol}$ chlide $\mathrm{g}^{-1} \mathrm{DW}$ ), and carbonic anhydrase (CA) activity $\left(\mu \mathrm{CO}_{2} \mathrm{~kg}^{-1} \mathrm{DW} \mathrm{s}^{-1}\right)$.

\begin{tabular}{|lllll|}
\hline & Parameters & & \\
\cline { 2 - 5 } Treatments & Chl content & $\delta$-ALAD activity & Chlase activity & CA activity \\
\hline Control & $9.27 \pm 0.19^{\mathrm{ab}}$ & $110.46 \pm 5.39^{\mathrm{b}}$ & $8.51 \pm 0.56^{\mathrm{fg}}$ & $1468.37 \pm 44.67^{\mathrm{bc}}$ \\
\hline KEG & $9.85 \pm 0.28 \mathrm{a}$ & $128.51 \pm 3.61^{\mathrm{a}}$ & $6.42 \pm 0.39^{\mathrm{h}}$ & $1563.79 \pm 51.32^{\mathrm{b}}$ \\
\hline K+PEG & $4.67 \pm 0.35^{\mathrm{d}}$ & $74.08 \pm 7.82^{\mathrm{g}}$ & $11.58 \pm 1.20^{\mathrm{de}}$ & $1165.52 \pm 88.69^{\mathrm{d}}$ \\
\hline K+PEG+TEA & $3.58 \pm 0.10^{\mathrm{c}}$ & $108.44 \pm 2.81^{\mathrm{bc}}$ & $9.36 \pm 0.29^{\mathrm{f}}$ & $1987.65 \pm 66.00^{\mathrm{a}}$ \\
\hline K+PEG+HT & $3.09 \pm 0.35^{\mathrm{f}}$ & $88.72 \pm 2.88^{\mathrm{de}}$ & $13.61 \pm 0.35^{\mathrm{bc}}$ & $817.05 \pm 47.32^{\mathrm{f}}$ \\
\hline K+PEG+TEA+HT & $2.64 \pm 0.11^{\mathrm{g}}$ & $84.31 \pm 4.77^{\mathrm{ef}}$ & $14.88 \pm 0.47^{\mathrm{a}}$ & $634.82 \pm 71.98^{\mathrm{g}}$ \\
\hline
\end{tabular}


Data is mean of three independent replicates, with bars indicating SE. Bars with different letters indicate that differences were statistically significant at $p<0.05$ (DMRT). Double deionized water (control), $5 \mathrm{mM}$ $\mathrm{K}_{2} \mathrm{CO}_{3}(\mathrm{~K}), 15 \%(\mathrm{w} / \mathrm{v})$ polyethylene glycol $8000(\mathrm{PEG}), 20 \mathrm{mM}$ tetraethylammonium chloride (TEA, $\mathrm{K}^{+}$ channel blocker), and $1 \mathrm{mM}$ hypotaurine ( $\mathrm{HT}: \mathrm{H}_{2} \mathrm{~S}$ scavenger).

\section{Figures}
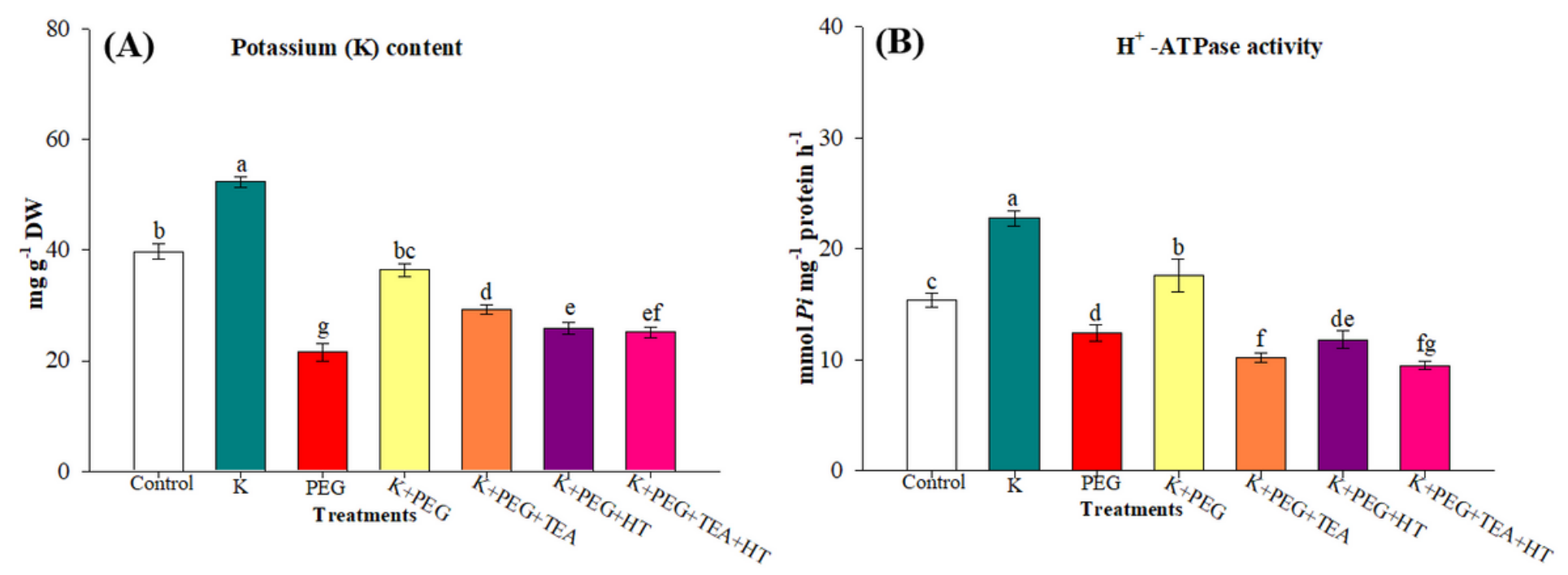

Figure 1

Effect of various treatments on (A) Leaf potassium (K) content and (B) and H+-ATPase activity in tomato

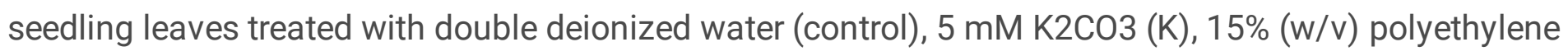
glycol 8000 (PEG), $20 \mathrm{mM}$ tetraethylammonium chloride (TEA, $\mathrm{K}+$ channel blocker), and $1 \mathrm{mM}$ hypotaurine (HT: H2S scavenger). Data is mean of three independent replicates, with bars indicating SE. Bars with different letters indicate that differences were statistically significant at $p<0.05$ (DMRT). 

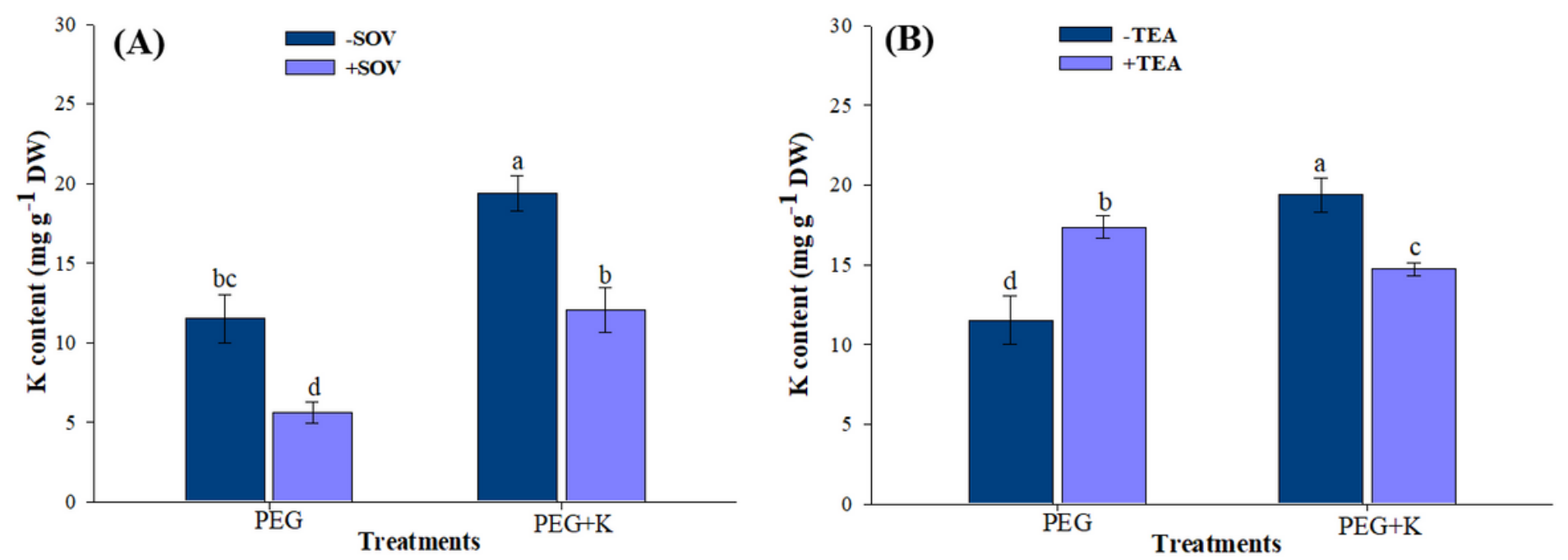

Figure 2

Effect of plasma membrane inhibitors on potassium $(\mathrm{K})$ content in tomato seedling leaves. Prior to $\mathrm{K}$ estimation, seedlings were treated with $500 \mu \mathrm{M}$ sodium orthovanadate (SOV: PM H+-ATPase inhibitor) or $20 \mathrm{mM}$ tetraethylammonium chloride (TEA: K-channel blocker) for $30 \mathrm{~min}$ followed by exposure to $15 \%$ $(\mathrm{w} / \mathrm{v})$ polyethylene glycol $8000(\mathrm{PEG})$ for $24 \mathrm{~h}$, in presence or absence of $\mathrm{K}$. Data is mean of three independent replicates, with bars indicating SE. Bars with different letters indicate that differences were statistically significant at $p<0.05$ (DMRT). 

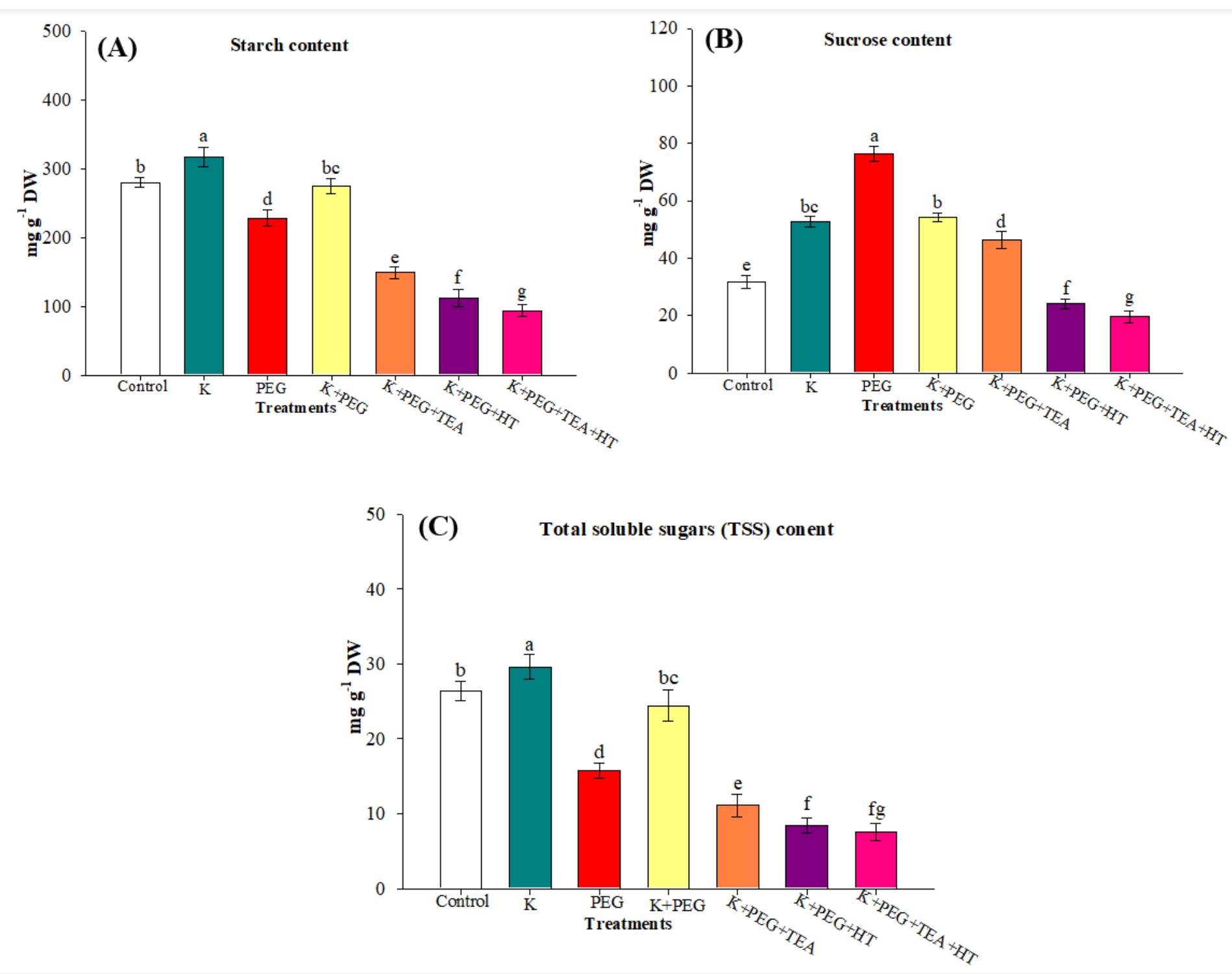

Figure 3

Effect of various treatments on the concentration of carbohydrates in tomato leaves. (A) Starch content, (B) Sucrose content, and (C) Total soluble carbohydrates (TSC) content. Double deionized water (control), $5 \mathrm{mM} \mathrm{K} 2 \mathrm{CO} 3(\mathrm{~K}), 15 \%(\mathrm{w} / \mathrm{v}$ ) polyethylene glycol 8000 (PEG), $20 \mathrm{mM}$ tetraethylammonium chloride (TEA, $\mathrm{K}+$ channel blocker), and $1 \mathrm{mM}$ hypotaurine (HT: H2S scavenger). Data is mean of three independent replicates, with bars indicating SE. Bars with different letters indicate that differences were statistically significant at $p<0.05$ (DMRT). 

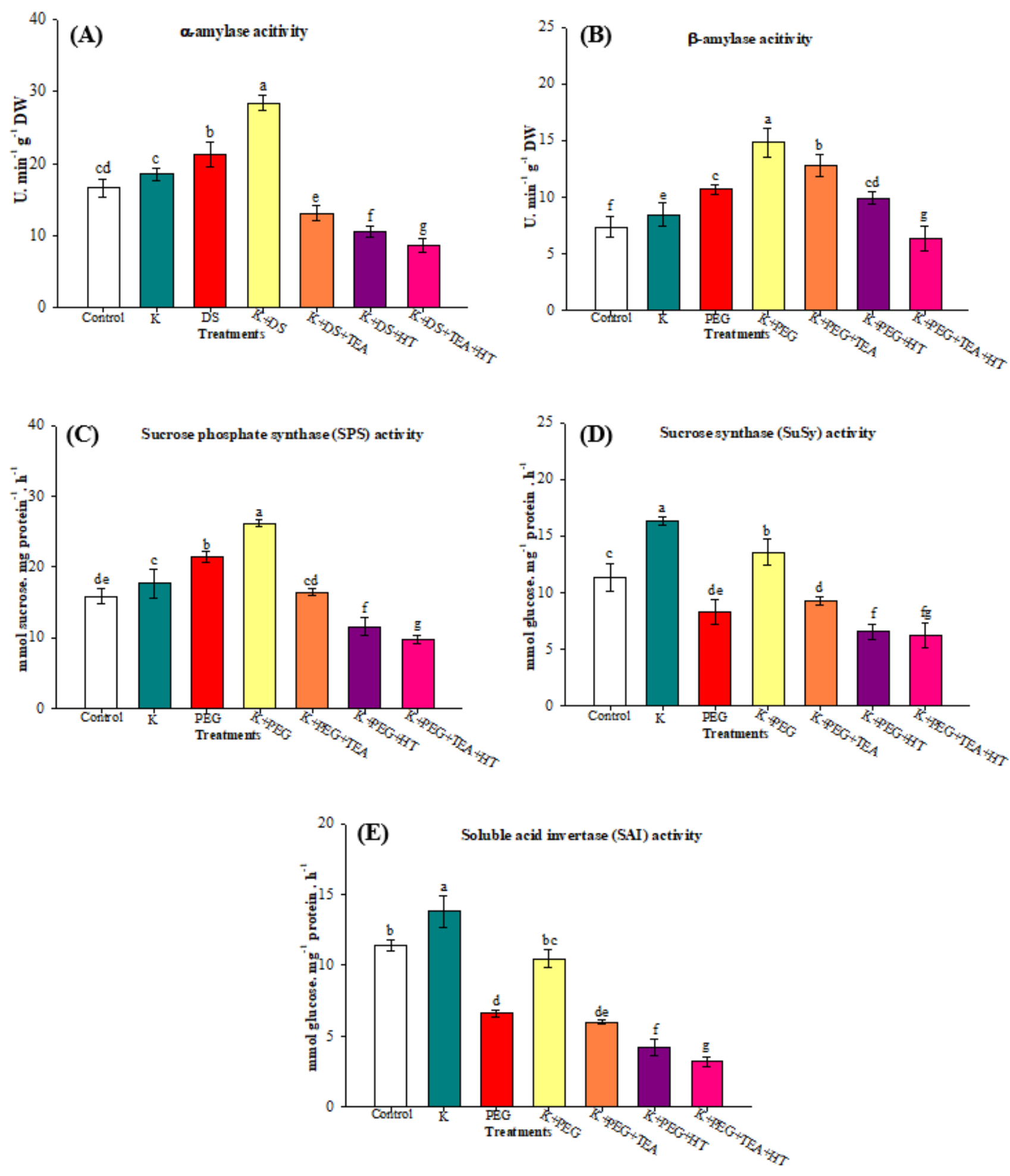

Figure 4

Activity of the enzymes associated with carbohydrate metabolism. (A) a-amylase activity, (B) $\beta$-amylase activity, (C) Sucrose phosphate synthase (SPS) activity, (D) Sucrose synthase (SuSy) activity, and (E)

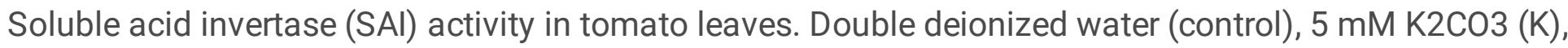
15\% (w/v) polyethylene glycol 8000 (PEG), $20 \mathrm{mM}$ tetraethylammonium chloride (TEA, K+ channel blocker), and $1 \mathrm{mM}$ hypotaurine (HT: H2S scavenger). Data is mean of three independent replicates, with 
bars indicating SE. Bars with different letters indicate that differences were statistically significant at $p<$ 0.05 (DMRT).
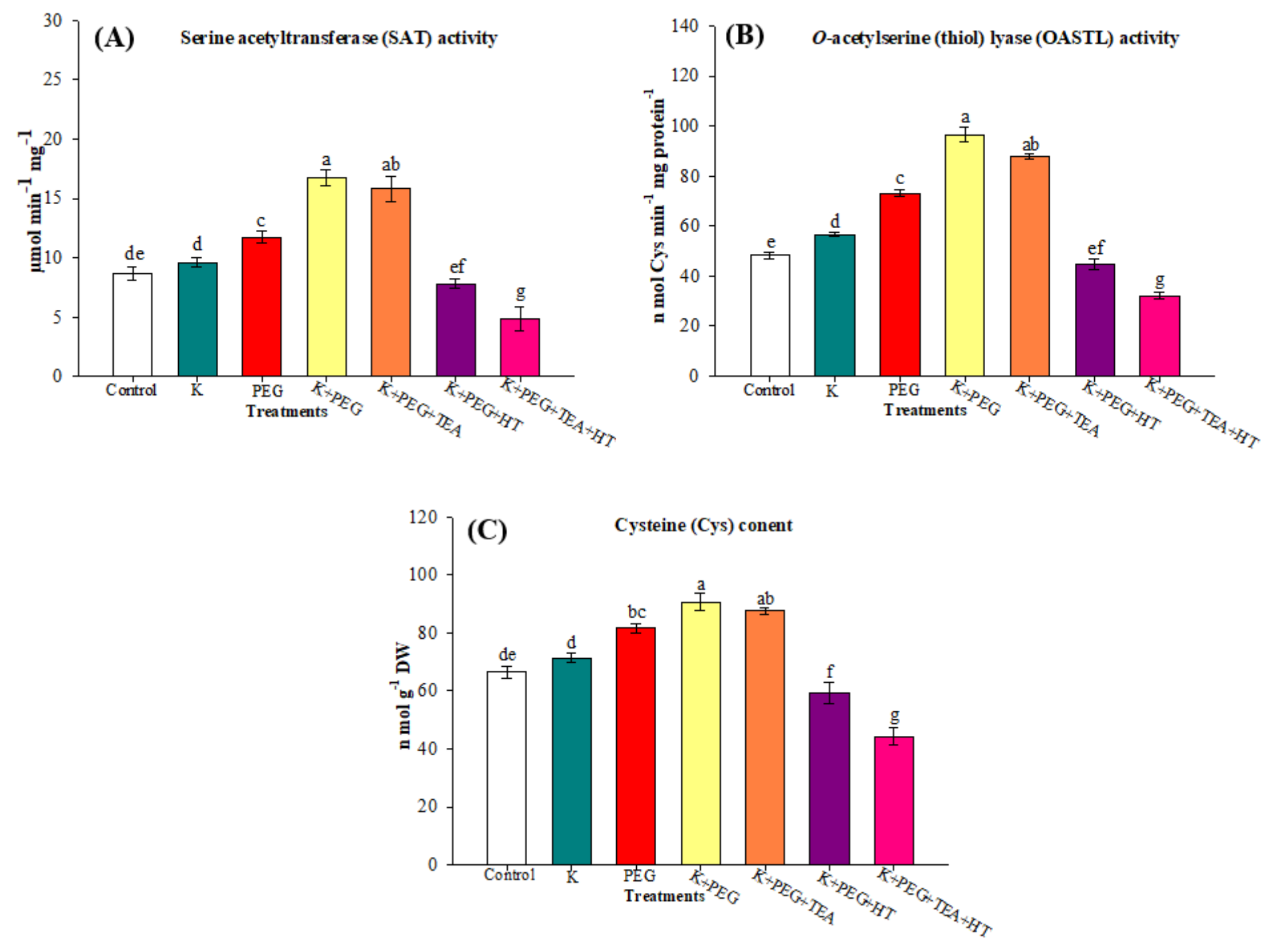

Figure 5

Cysteine (Cys) content and activity of its biosynthesizing enzymes in the leaves of tomato. (A) Serine acetyltransferase (SAT) activity, (B) O-acetylserine (thiol) lyase (OASTL) activity, and (D) Cys content. Double deionized water (control), $5 \mathrm{mM} \mathrm{K2CO3} \mathrm{(K),} \mathrm{15 \%} \mathrm{(w/v)} \mathrm{polyethylene} \mathrm{glycol} 8000$ (PEG), $20 \mathrm{mM}$ tetraethylammonium chloride (TEA, $\mathrm{K}+$ channel blocker), and $1 \mathrm{mM}$ hypotaurine (HT: H2S scavenger). Data is mean of three independent replicates, with bars indicating SE. Bars with different letters indicate that differences were statistically significant at $p<0.05$ (DMRT). 

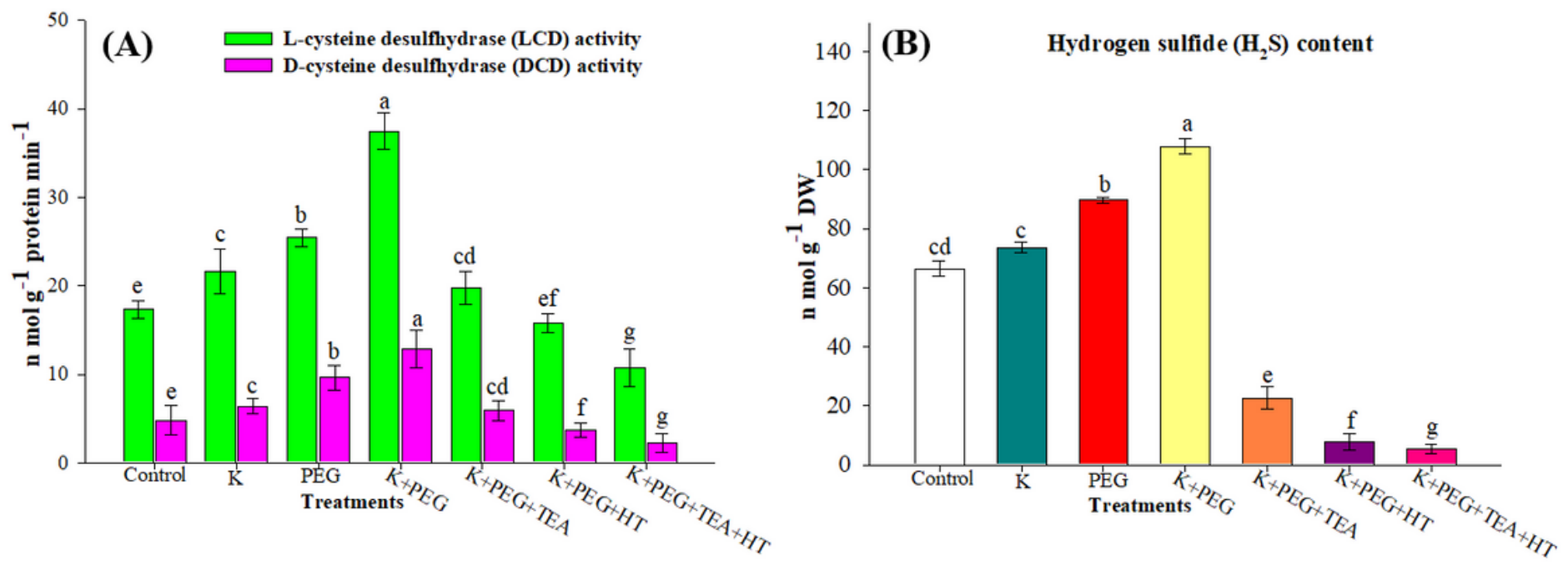

Figure 6

Effect of various treatments on the activity of biosynthesizing enzymes of hydrogen sulfide (H2S) and its concentration in tomato leaves. (A) Activity of L-cysteine desulfhydrase (LCD) and D-cysteine desulfhydrase (DCD) and (B) Hydrogen sulfide (H2S) content. Double deionized water (control), $5 \mathrm{mM}$ K2CO3 (K), 15\% (w/v) polyethylene glycol 8000 (PEG), 20 mM tetraethylammonium chloride (TEA, K+ channel blocker), and $1 \mathrm{mM}$ hypotaurine (HT: H2S scavenger). Data is mean of three independent replicates, with bars indicating SE. Bars with different letters indicate that differences were statistically significant at $p<0.05$ (DMRT). . 

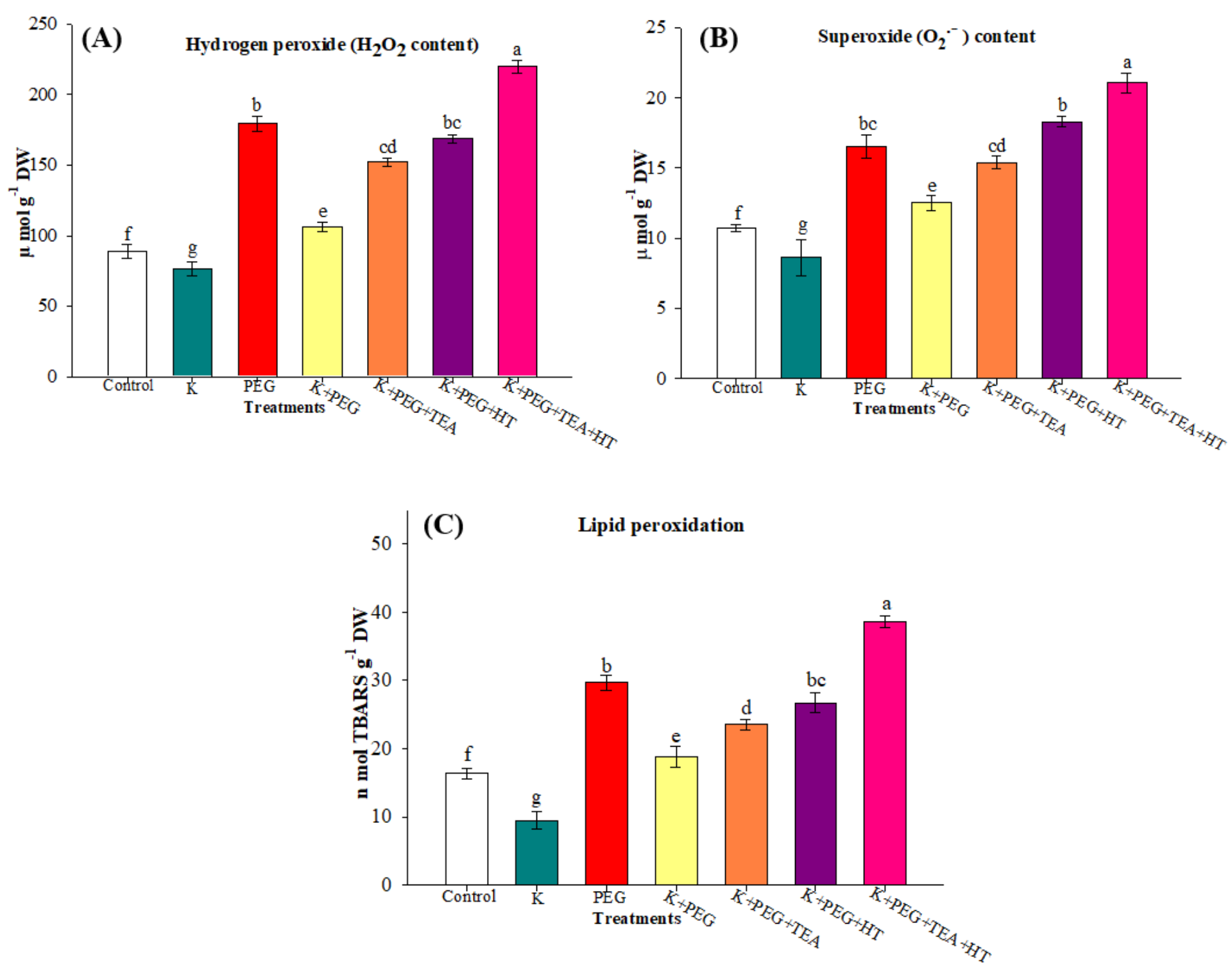

Figure 7

Reactive oxygen species production and associated damage in the leaves of tomato. (A) Hydrogen peroxide (H2O2) content, (B) Superoxide (02•-) content, and (C) Lipid peroxidation. Double deionized water (control), $5 \mathrm{mM} \mathrm{K2CO3} \mathrm{(K),} \mathrm{15 \%} \mathrm{(w/v)} \mathrm{polyethylene} \mathrm{glycol} 8000$ (PEG), $20 \mathrm{mM}$ tetraethylammonium chloride (TEA, $\mathrm{K}+$ channel blocker), and $1 \mathrm{mM}$ hypotaurine (HT: H2S scavenger). Data is mean of three independent replicates, with bars indicating SE. Bars with different letters indicate that differences were statistically significant at $p<0.05$ (DMRT). 


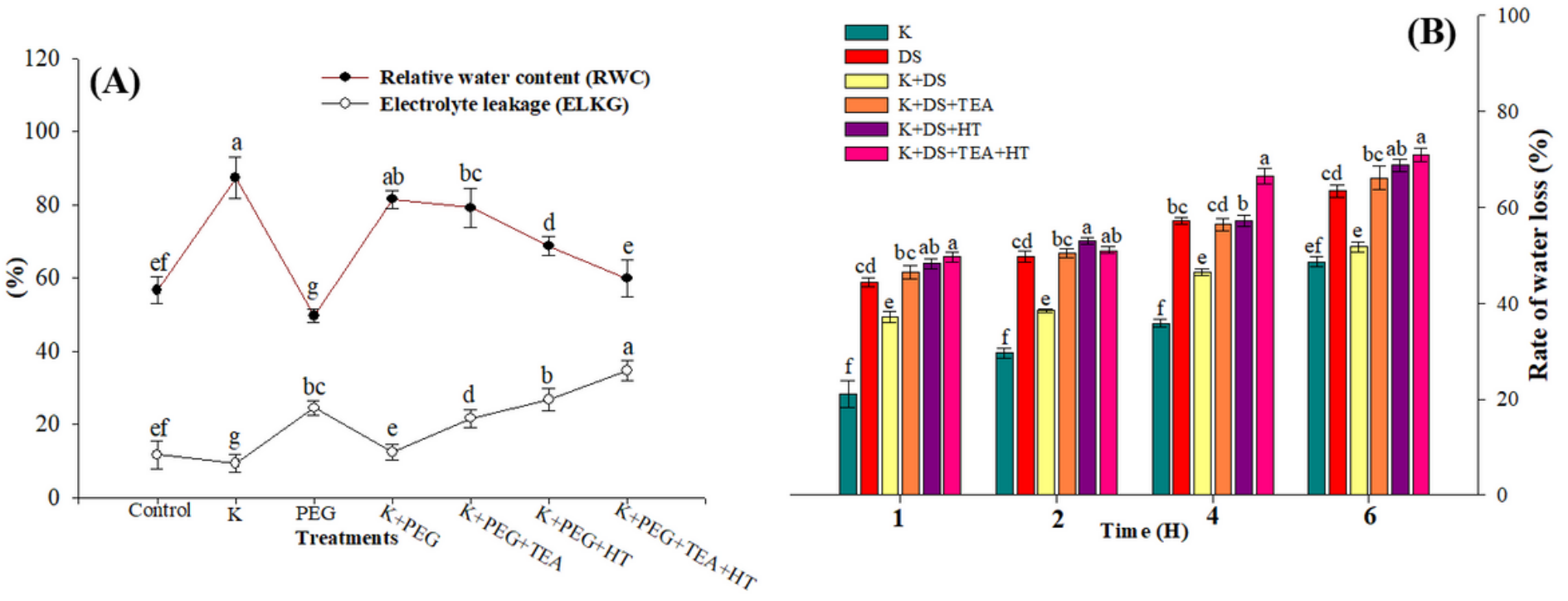

Figure 8

Effect of treatments on the stress markers in tomato seedlings. (A) Relative water content and electrolyte leakage and (B) Rate of water loss at different intervals. Double deionized water (control), $5 \mathrm{mM} \mathrm{K2CO3}$ $(\mathrm{K}), 15 \%(\mathrm{w} / \mathrm{v}$ ) polyethylene glycol 8000 (PEG), $20 \mathrm{mM}$ tetraethylammonium chloride (TEA, K+ channel blocker), and $1 \mathrm{mM}$ hypotaurine (HT: H2S scavenger). Data is mean of three independent replicates, with bars indicating SE. Bars with different letters indicate that differences were statistically significant at $p<$ 0.05 (DMRT). 

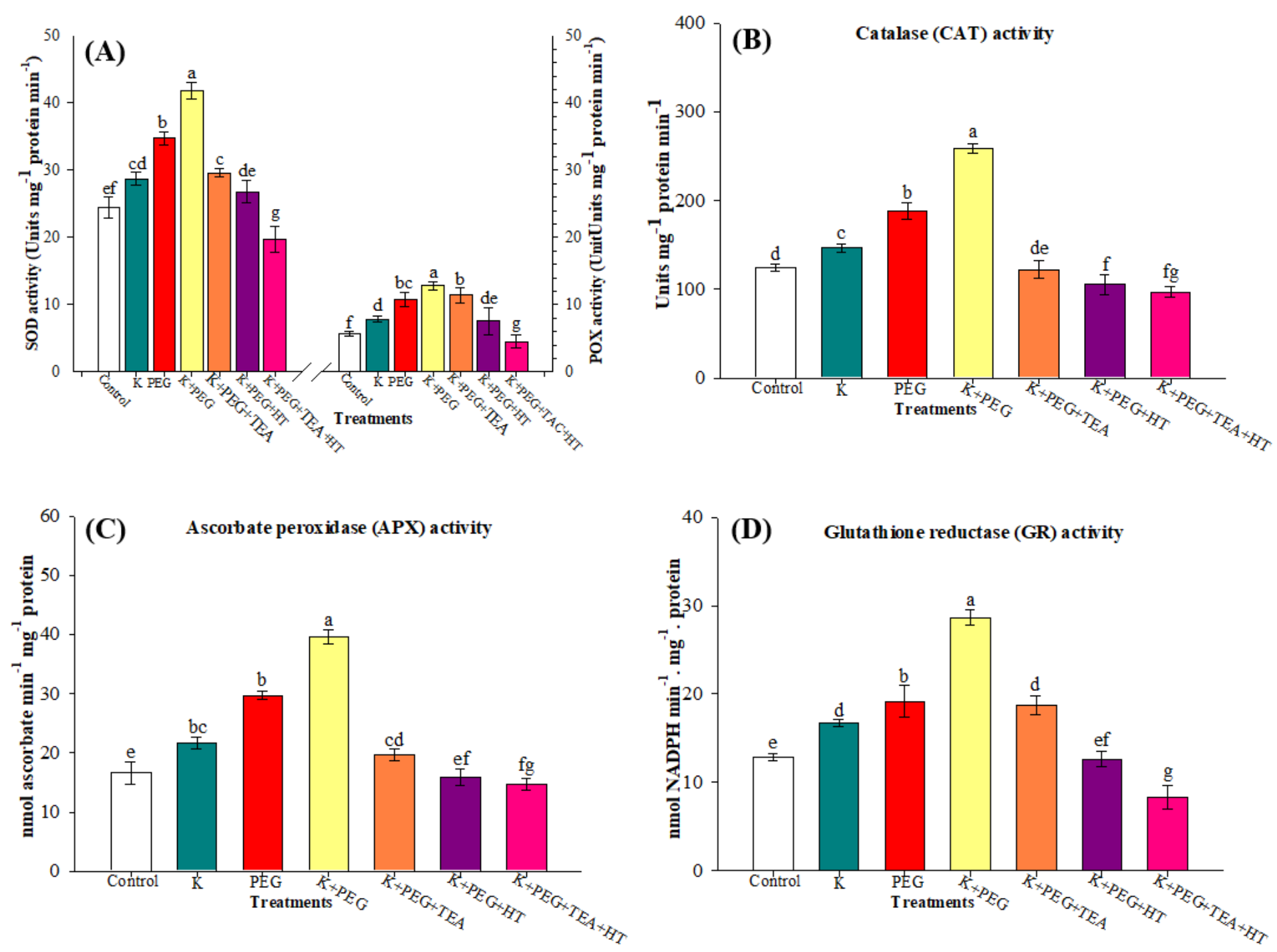

Figure 9

Activity of antioxidant enzymes in tomato seedlings. (A) Superoxide dismutase (SOD) and peroxidase (POX) activity, (B) Catalase (CAT) activity, (C) Ascorbate peroxidase (APX) activity and (D) Glutathione

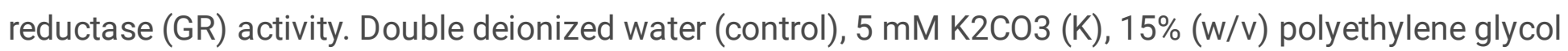
8000 (PEG), 20 mM tetraethylammonium chloride (TEA, K+ channel blocker), and $1 \mathrm{mM}$ hypotaurine (HT: $\mathrm{H} 2 \mathrm{~S}$ scavenger). Data is mean of three independent replicates, with bars indicating SE. Bars with different letters indicate that differences were statistically significant at $p<0.05$ (DMRT). 


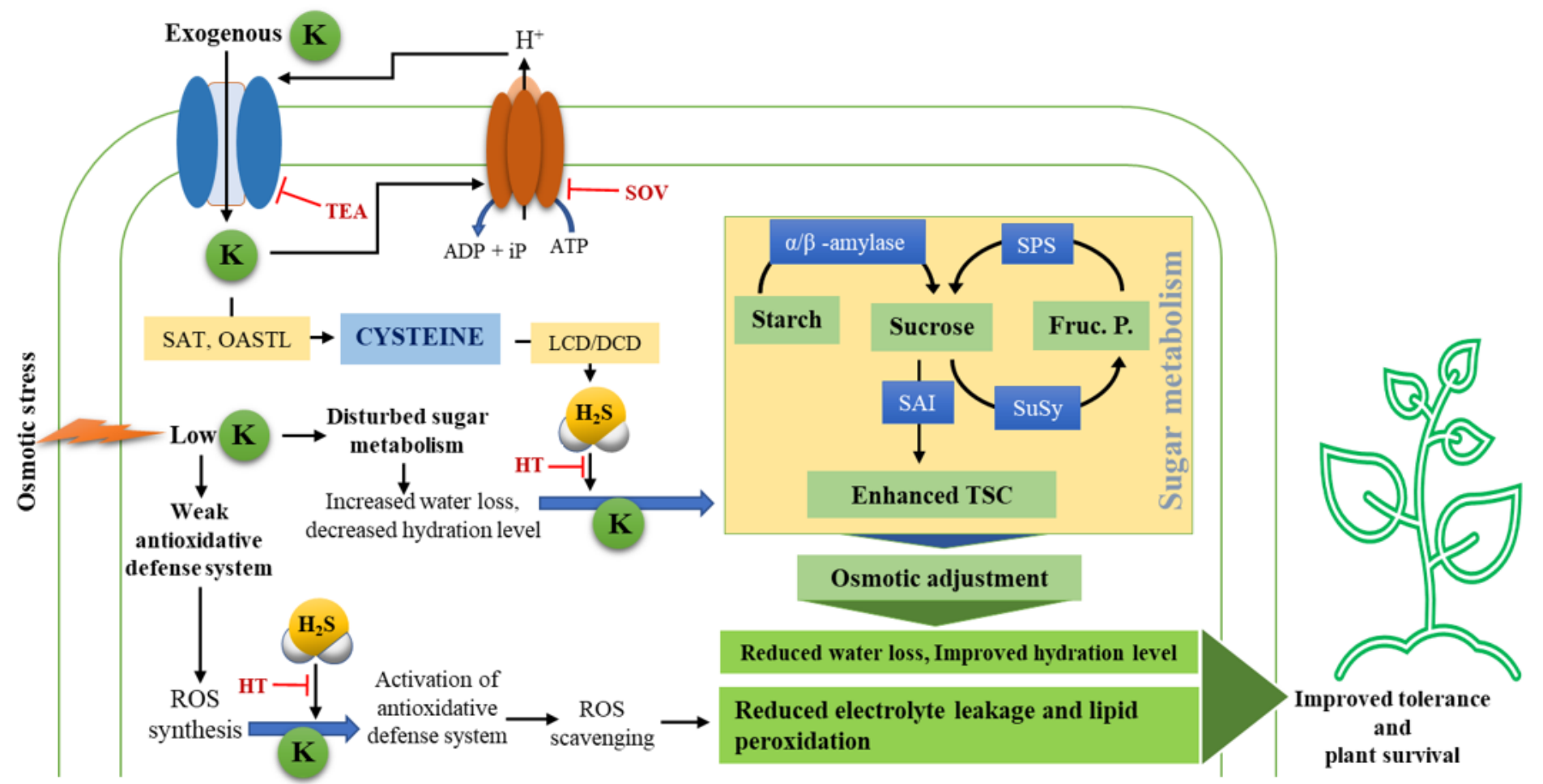

Figure 10

Diagrammatic representation of the role of potassium $(\mathrm{K})$ and hydrogen sulfide $(\mathrm{H} 2 \mathrm{~S})$ in the regulation of sugar metabolism and antioxidative defense system under osmotic stress. DCD: D-cysteine desulfhydrase, Fruc. P.: Fructose-6-phosphate, HT: hypotaurine, LCD: L-cysteine desulfhydrase, OASTL: Oacetylserine (thiol) lyase, ROS: Reactive oxygen species, SAI: Soluble acid invertase, SAT: Serine acetyltransferase, SOV: Sodium ortho vanadate (H+-ATPase inhibitor), SPS: Sucrose phosphate synthase, SuSy: Sucrose synthase, TEA: Tetraethylammonium chloride (K Channel blocker), TSC: Total soluble carbohydrates 